\title{
DE FALSEDADES, MENTIRAS Y OTRAS TÉCNICAS QUE FALTAN A LA VERDAD PARA INFLUIR EN LA OPINIÓN PÚBLICA ${ }^{1}$
}

\author{
ROSARIO SERRA CRISTÓBAL \\ Catedrática de Derecho Constitucional \\ Universitat de València
}

TRC, n. ${ }^{\circ} 47,2021$, pp. 199-235

ISSN 1139-5583

\begin{abstract}
SUMARIO
I. El disenso en democracia vs. la proliferación de determinados mensajes no amparables en el ordenamiento. II. El fácil influjo de determinados mensajes falsos en la opinión pública en la era de internet. III. La complicada determinación de lo que es verdad y lo que es mentira. IV. La compleja disociación entre hechos y opiniones. La veracidad sobre los hechos y los límites a las opiniones. V. ¿Caben los mensajes que, faltando a la verdad, violentan los valores y principios básicos de nuestro ordenamiento? VI. De la ideología personal a la falsedad deliberada o la intención de mentir. VII. Controles en la red de los mensajes falsos. VIII. A modo de conclusión: «Fiat veritas ne pereat mundus».
\end{abstract}

\section{EL DISENSO EN DEMOCRACIA VS. LA PROLIFERACIÓN DE DETERMINADOS MENSAJES NO AMPARABLES EN EL ORDENAMIENTO}

En un Estado que se considera democrático, cualquier afirmación o cualquier información tiene que poder ser discutida. Lo cual significa, por un lado, que no cabe establecer una verdad única ni conformar una opinión pública de tal modo que de facto se imponga aquella de forma general, y, por otro lado, que es necesario garantizar la capacidad libre e informada de disentir sobre cualquier asunto,

1 Este trabajo se inserta en el marco del Proyecto de Investigación Seguridad Pública, Seguridad Privada y Derechos Fundamentales, RTI2018-098405-B-100, del Ministerio de Ciencia, Innovación y Universidades. 
incluso admitiendo opiniones que puedan molestar al Estado o a un conjunto de la población ${ }^{2}$. Como señalaba Revenga Sánchez, «la fortaleza del sistema democrático radica en admitir, más aún, en propiciar, el cuestionamiento permanente de las decisiones que adoptan y ejecutan quienes tienen legitimidad para hacerlo. En democracia no hay verdades oficiales de naturaleza trascendente, ni ámbitos de decisión vedados a la confrontación pública» ${ }^{3}$. De hecho, como defiende Villaverde Menéndez, hallar la verdad no es el objeto del debate de ideas, en el cual ningún mensaje puede arrogarse privilegio alguno apelando a su condición de verdadero ${ }^{4}$. Ahora bien, en el debate público, junto al intercambio de ideas, se produce en numerosas ocasiones una transmisión de información o se expresan ideas que se sustentan en hechos que —estos sí- pueden ser veraces o no.

También es cierto que, en ese debate público, aun admitiendo que el disenso e incluso la crítica feroz son admisibles, en ocasiones cabe poner coto a la transmisión pública de ciertas expresiones e informaciones cuando dañan derechos o valores fundamentales recogidos en el ordenamiento jurídico. En este trabajo, nos interesa especialmente plantear la cuestión cuando ese daño se genera porque lo que se transmite falta a la veracidad ${ }^{5}$, lo cual puede suceder cuando se ejerce la libertad de información, pero también cuando se transmiten opiniones acompañadas de una base fáctica deliberadamente falsa; o simplemente podríamos preguntarnos si la libertad de expresión $\left(\right.$ política $^{6}$ ) permite mentir y en qué ocasiones,

2 De ese modo lo indicaba ya hace años el TEDH con palabras que siguen teniendo vigencia hoy en día. Decía en el asunto Hadyside, de 7 de diciembre de 1976, que «Al amparo el art. 10.2 son válidas no sólo las informaciones o ideas recibidas favorablemente, o contempladas como inofensivas o indiferentes, sino también aquellas otras capaces de ofender, sacudir o molestar al Estado o a un sector de la población. Así lo reclama el pluralismo, la tolerancia y la amplitud de miras, sin las cuales no hay sociedad democrática» (par. 49). Idem en STEDH asunto Otegui Mondragón c. España, de 15/03/2011, Asunto Eon c. Francia, de 14/03/2013, Asunto Toranzo Gómez c. España, de 20/11/2018 y Asunto Terentyev c. Rusia, de 28/08/2018. Sobre la jurisprudencia del TEDH en materia de libertad de expresión puede verse, asimismo: Presno Llierna, M. Á., «La libertad de expresión según el Tribunal Europeo de Derechos Humanos», Revista de la Facultad de Derecho de México, n. ${ }^{\circ}$ 276, 2020. Revenga SÁnchez, M. et. al., Tendencias jurisprudenciales de la Corte Interamericana y el Tribunal Europeo de Derechos Humanos. Derecho a la vida. Libertad personal. Libertad de expresión. Participación política, Valencia, Tirant lo Blanch, 2008. CATALÀ I BAS, A., Libertad de expresión e información: la jurisprudencia del TEDH y su recepción por el Tribunal Constitucional: hacia un derecho europeo de los derechos humanos, Valencia, Ediciones Revista General de Derecho, 2001. También el TC español ha indicado que la libertad de expresión comprende la libertad de crítica, incluyendo los supuestos en que se «pueda molestar, inquietar o disgustar a quien se dirige, pues así lo requieren el pluralismo, la tolerancia y el espíritu de apertura, sin los cuales no existe sociedad democrática» (STC 176/2006, de 5 de junio).

3 Revenga Sánchez, M., Seguridad Nacional y Derechos Humanos. Estudios sobre la jurisprudencia del Tribunal de Estrasburgo, Cizur Menor, Aranzadi, 2002, p. 127.

4 Villaverde Menéndez, I., «Verdad y Constitución. Una incipiente dogmática de las ficciones constitucionales», REDC, n. ${ }^{\circ} 106,2016$, pp. 149-201.

5 Azurmendi AdARraga, A., «De la verdad informativa a la «información veraz» de la Constitución española de 1978. Una reflexión sobre la verdad exigible desde el derecho de la información», Comunicación y Sociedad, Vol. XVIII, n. ${ }^{\circ}$ 2, 2005, pp. 9-48.

6 La libertad de expresión política tiene como objetivo principal estimular la toma de decisiones del individuo, la convergencia de una pluralidad de opiniones y la libre circulación de la información pública. Esquivel Alonso, Y., Libertad de expresión política y propaganda negativa, Valencia, Tirant lo Blanch, 2018. 
me refiero a intervenir en el debate público para expresar criticas, defender y propagar las propias ideas o con cualquier otra finalidad, transmitiendo hechos que faltan a la veracidad, incluso a veces, son radicalmente falsos.

Cabe incluso plantearse si existe un derecho a mentir, cuestión que abrió un intenso debate entre Kant y Constant. El tema sobre el que polemizaron fue sobre la existencia de un deber incondicionado de decir siempre la verdad. Para Kant, situándose en el plano de la moral, defendía que «ser verdadero/verídico (honesto) en todas nuestras declaraciones» es un sagrado mandato de la razón ${ }^{7}$, es un deber incondicionado ${ }^{8}$. Constant discrepaba al defender que: «el principio moral que declara ser un deber decir la verdad, si alguien lo tomase incondicional y aisladamente, tornaría imposible cualquier sociedad (...) Este principio, aislado, resulta inaplicable. Destruiría la sociedad» ${ }^{9}$. En definitiva, este segundo autor defendió que hay supuestos en los que ese deber queda desplazado, aportando ejemplos concretos de situaciones en las que decir la verdad podría equivaler a hacer mal, situándose en una posición que no se articula bien con la idea de que no es conveniente mentir al pueblo en ningún caso, que había defendido Condorcet $^{10}$.

La pregunta es cuándo podemos decir que se ha cruzado esa línea roja que separa lo que aún cabe considerar crítica, o defensa de puntos de vista discrepantes u opiniones políticas sustentadas en hechos veraces, de las opiniones o informaciones que manipulan los hechos que transmiten e incluso incurren en la falsedad o en la mentira, más incardinable en lo que ha venido a denominarse fake news o desinformación. El problema es que, cuando esto sucede, ello repercute negativamente en la conformación de esa deseable opinión pública libre, y crea una sociedad que no es capaz de ponerse de acuerdo sobre hechos básicos, lo que impide construir una democracia funcional ${ }^{11}$. Porque la democracia se asienta sobre un debate público, plural e informado; no solo la libre opinión, sino igualmente la información es esencial. Sánchez Ferriz advertía que se precisa de una información completa y verídica, que cree un clima de confianza. «El público

7 KANT, I., «Acerca de la ilegitimidad de la mentira» (1796) y «Acerca de un pretendido derecho a mentir por filantropía» (1797), KANT, I. y CONSTANT, B., ¿Hay derecho a mentir? (La polémica Immanuel Kant y Benjamin Constant) (Estudio preliminar de Gabriel Albiac), Madrid, Tecnos, 2012, p. 30.

8 Ibidem, p. 33.

9 Constant, B., «Decir la verdad no es un principio general al que tengan derecho todos los hombres» (1796), KANT, I. y CONSTANT, B., ¿Hay derecho a mentir?..., op. cit., pp. 18-19.

10 El Marqués de Condorcet disertó sobre los errores o mentiras en las que el pueblo podía caer, y sobre la necesidad o la inconveniencia de decir al pueblo toda la verdad. Condorcet concluía rechazando el derecho del gobernante a mentir al pueblo incluso por el bien de este, pues, ¿cómo puede nadie asegurar que el poderoso no utilizará la mentira para hacer el mal una vez se le haya permitido emplearla para hacer el bien. MARQUÉS DE CONDORCET, «Disertación filosófica y política o reflexión sobre esta cuestión: ¿Es útil para los hombres ser engañados?», DE LuCAs, J., ¿Es conveniente engañar al pueblo? (Castillón-Becker-Condorcet. Política y filosofía en la ilustración: el concurso de 1778 de la Real Academia de Ciencias de Berlín), Madrid, CEC, 1991.

11 Pauner Chulvi, C., «Noticias falsas y libertad de expresión e información. El control de los contenidos informativos en la red», TRC, n. ${ }^{\circ} 41,2018$, p. 299. 
preferirá que se le diga lo peor —al menos así podrá reaccionar tomando una postura basada en la realidad-a saberse engañado» ${ }^{12}$.

En definitiva, lo que interesa es determinar si hay afirmaciones, - bien provenientes del gobierno o de ciudadanos o de asociaciones o partidos políticos, no importa-, que, por su absoluto desprecio al rigor informativo o por su manifiesta intención de engañar, no son admisibles. La democracia exige libertad informativa y de expresión, exige participación y debate, pero en esa interacción hay unas mínimas reglas de juego que deben respetarse cuando ciertas expresiones o la comunicación de determinados hechos falaces confrontan con bienes jurídicos constitucionalmente protegidos. Posiblemente debamos determinar cuáles son esos mínimos exigibles para una pacífica convivencia, si queremos hablar de una garantía democrática básica.

\section{EL FÁCIL INFLUJO DE DETERMINADOS MENSAJES FALSOS EN LA OPINIÓN PÚBLICA EN LA ERA DE INTERNET}

El poder que otorga el manejo de información, — no solo la veraz sino también la falsa-, para la conformación de la opinión de la ciudadanía es una realidad de la que se es consciente ya hace muchos años ${ }^{13}$. Tal vez lo que ha cambiado es la ingente cantidad de información de la que se dispone hoy y los efectos que ello genera. La sociedad de la información en la que vivimos ofrece tantas fuentes informativas por vía tradicional o telemática que hace difícil al ciudadano hacerse con la imagen completa de todos los datos como para tener una opinión verdaderamente contrastada y, por lo tanto, fundada. Innenarity advertía de que la creciente complejidad de lo político en nuestras democracias dificulta que haya una opinión pública competente a la hora de entender y juzgar lo que está pasando, algo que entra en plena contradicción con uno de los presupuestos normativos básicos de la democracia. Cuando los ciudadanos o electores no consiguen comprender lo que está en juego, entonces la libertad de opinión y decisión pueden ser consideradas un reconocimiento formal irrealizable ${ }^{14}$.

En este campo de la superinformación es donde determinados mensajes pueden acabar calando en la opinión pública frente a otros, cosa que puede suceder de manera fortuita o, en la mayor parte de las ocasiones, de una forma pretendida. De hecho, se habla del empleo de las emociones en las democracias

12 SÁnChez Ferriz, R., El derecho a la información, Valencia, Cosmos, 1974, p. 63.

13 En este sentido indicaba Ignacio Villaverde que «la realidad es que la libertad de expresión relevante socio-políticamente ya no es la que ejerce el individuo aislado, sino la que ejercen los medios de comunicación. Ellos son los que trazan las grandes líneas informativas, los que crean corrientes de opinión... Sencillamente, la mayoría escucha y lee lo que los medios dicen, no lo que divulga el orador en la esquina de la calle», Villaverde Menéndez, I., «Los derechos del público: la revisión de los modelos clásicos de "proceso de comunicación pública"», REDC, n. ${ }^{\circ}$ 68, 2003, p. 126.

14 Innerarity, D., Comprender la democracia, Barcelona, Gedisa Editorial, 2018, p. 32. 
actuales, de lo que ha venido a denominarse «emocracia» ${ }^{15}$. Consiste en propiciar la comunicación o trasmisión de emociones que acaban predominando sobre la razón. Son lo que la filósofa Nussbaum denomina emociones públicas o políticas ${ }^{16}$. Ello conduce a la formación de una voluntad colectiva, basada en las emociones mayoritariamente aceptadas de forma colectiva y exacerbadas por quien tiene la capacidad de hacerlo (los medios, los gobiernos, movimientos políticos, líderes...) Ya hablaba Aristóteles, en su Retórica, de las emociones ${ }^{17}$ y explicaba cómo el buen orador conoce el arte de utilizarlas y provocarlas en el público para conseguir de él que haga lo que debe, en el mejor de los casos, o, en el peor de los casos, que haga lo que al orador o al político le interesa. Explicaba de qué forma el discurso público puede cambiar el estado de ánimo de quienes lo escuchan, gracias al uso de los tópicos, las figuras del lenguaje, y el poder de la elocuencia. Eso mismo es lo George Orwell parecía querer decir con aquello de que «El lenguaje político...está diseñado para hacer que las mentiras suenen confiables y el asesinato respetable; y para darle la apariencia de solidez al mero viento ${ }^{18}$.

En ocasiones, todo ello conduce al final a lo que se ha denominado posverdad. Como se ha indicado, este término ${ }^{19}$ ha venido reflejando que aquello que las personas sienten ante un estímulo, sus emociones respecto de una idea o de un líder o sus sensaciones subjetivas influyen de una forma más efectiva en la toma de decisiones que los datos y estadísticas objetivas o los hechos comprobados, siendo más importantes para ellos que la verdad. Se señalaba a Donald Trump como el máximo exponente de la política posverdad, una confianza en afirmaciones que se «sienten verdad», pero no se apoyan en la realidad. «La posverdad, por tanto, puede ser una mentira asumida como verdad o incluso una mentira asumida como mentira, pero reforzada como creencia o como un hecho compartido en una

15 Arias Maldonado, M., La democracia sentimental: politica y emociones en el s. XXI, Barcelona, Página indómita, 2016. CAMPS, V., El Gobierno de las emociones, Herder Editorial, 2012. Fajardo Fajardo, C., La emocracia global y otros escritos, Bogotá, ediciones Desde abajo, 2018. Término también empleado por E. GórRIz RoYo para referirse a las respuestas al terrorismo en «Contraterrorismo a raíz de la Directiva (UE) 2017/541 y europeización del derecho penal al enemigo: ¿necesidad de reformas en la legislación penal española?», GonzÁlez Cussac, J.L. y Flores Giménez, F., (Coords.) Seguridad y Derechos. Análisis de las amenazas, evaluación de las respuestas y valoración del impacto en los derechos fundamentales, Valencia, Tirant lo Blanch, 2018, pp. 553 y ss.

16 Las emociones políticas o públicas son para Nussbaum aquellas que «tienen como objeto la nación, los objetivos de la nación, las instituciones y los dirigentes de esta, su geografía, y la percepción de los conciudadanos como habitantes con los que se comparte un espacio público común». Ello supone que, dado cualquier proyecto socio-político, debamos preguntarnos cuáles son las emociones que queremos activar en la ciudadanía con el fin de que nos ayuden en su logro. Nussbaum, M., Emociones políticas. ¿Por qué el amor es importante para la justicia?, Barcelona, Paidós, 2014, p. 14.

17 Aristóteles, Retórica, (Introducción y traducción de Alberto Bernabé) Ed. 2014, Madrid, Alianza editorial, 2014.

18 Orwell, G., 1984, Barcelona, Edicions 62, 2005.

19 El término fue acuñado por el sociólogo norteamericano R. Keyes en su trabajo Post-truth, publicado en 2004 . 
sociedad $»^{20}$. La cuestión es que la posverdad no constituye un arma solo a disposición de la clase política dominante, sino que el uso de la misma supone un recurso poderosísimo para aquellos recientes movimientos que quieren alcanzar el poder o afianzar en la opinión pública determinados mensajes extremos, populistas o excluyentes.

En el debate político, junto a ese predominio de los argumentos emocionales sobre los racionales, no es extraño encontrar mensajes que recurren a la simplificación dicotómica del discurso, a la promesa de medidas políticas o sociales o la utilización de afirmaciones destinadas todas ellas a ganarse la adhesión de la población, y a discursos demagógicos, populistas o extremos. El problema es cuando todas esas herramientas, que son legítimas en democracia, empiezan a ser sustituidas por verdades a medias, informaciones tergiversadas e incluso falsedades que causan — todas ellas — un impacto notable en la opinión pública. La inquietud aparece cuando la mentira y el engaño se convierten en un instrumento con el que influir en el proceso democrático.

Y la preocupación mayor surge cuando las falsedades o mentiras generan daño a los valores constitucionales básicos o a derechos de terceros o buscan infundir en la opinión pública el odio o rechazo hacia determinados colectivos. De hecho, entre los mensajes utilizados por determinados movimientos o líderes políticos no faltan aquellos que podríamos encuadrar dentro de lo que se conoce genéricamente como discurso del odio o de la discriminación ${ }^{21}$. El recurso a mensajes que atribuyen falsamente a determinados colectivos la culpa de alguno de los «males» del país es más que habitual ${ }^{22}$. Numerosas veces se trata de campañas de difusión del miedo que ayudan a extender entre sectores de la población ese pensamiento acrítico e irracional del que hablábamos anteriormente y el rechazo a determinados colectivos ${ }^{23}$. En un epígrafe posterior nos referiremos más a estas cuestiones. El caso es que, no pocas veces, se consigue que los ciudadanos dejen de opinar conforme a parámetros de valores colectivos, de los valores y principios que nos hemos dado en democracia, y pasen a construir su pensamiento desde un seguidismo acrítico que repite eslóganes que faltan a la verdad y discriminan.

20 Aмón, R., «Posverdad, palabra clave del año», El País, 17/11/2016.

21 Incluimos aquí los delitos de odio y los delitos de discurso del odio, en todas sus manifestaciones.

22 Ausín, T., «Cuéntame un cuento. Sobre mentiras y silencios en el ámbito de la información», Cuadernos del Ateneo, 2008, n. ${ }^{\circ} 25$, p. 20.

23 Tenemos sobrados ejemplos de mensajes muy comunes en las narrativas de algunos partidos políticos o líderes que utilizan el discurso del miedo (infundado) para potenciar su ideología: el miedo a que los extranjeros hurten posibilidades de trabajo a los nacionales, a los islamistas que se presumen todos terroristas, a ser víctima de un delito por parte de los inmigrantes que entran en nuestras fronteras sin recursos económicos, a que determinados discursos feministas o los colectivos LGTBI acaben con el tradicional concepto de familia, etc... Como muestra, en junio de 2020, el recién reelegido como Presidente de Polonia, el populista Andrzej Duda, del partido Ley y Justicia, declaraba: «Los LGTB no son el pueblo; son una ideología más destructiva que el comunismo», y atacó a su adversario político en la campaña electoral, que defendía los intereses del colectivo, acusándolo de querer la «sexualización de los niños» y «la destrucción de la familia». EFE, «Presidente polaco carga contra la 'ideología LGTB’ durante campaña electoral», La Vanguardia, 13/06/2020. 
En una línea parecida, hemos de plantearnos qué sucede con los mensajes que se sustentan en datos falsos que incitan a la población a actuar de un determinado modo, poniendo con ello en riesgo otros valores importantes como la seguridad o la salud. El ejemplo paradigmático lo encontramos en la proliferación de discursos negacionistas (y proselitistas) sobre la gravedad de la Covid-19 que invitan a no hacer uso de mascarillas, la distribución masiva de mensajes falsos sobre remedios a la enfermedad o las falsedades difundidas sobre las vacunas contra el virus. Son todo muestras de la trascendencia de analizar si cabe establecer límites a la libertad de expresión cuando esta va acompañada o sustentada en datos que se saben falsos y, además, ello puede generar un perjuicio para determinados individuos o para la colectividad.

Está demostrado el enorme poder político que la desinformación y los bulos pueden tener en ciertos momentos en la opinión pública y cómo los canales electrónicos de comunicación pueden potenciar su influencia ${ }^{24}$. Así se ha comprobado durante la pandemia del Covid-19, pero ya se había hecho con anterioridad. No hay más que recordar cómo la circulación de noticias falsas y la manipulación de la opinión de los ciudadanos a través de las redes sociales estuvo detrás de acontecimientos como el resultado del referéndum del Brexit o la victoria de Donald Trump en las elecciones presidenciales de 2016, donde no pocas voces apuntaron hacia el gobierno ruso como el artífice de las webs y redes sociales que estuvieron detrás de aquellas noticias falsas. Se han obtenido pruebas concluyentes de que los hackers soviéticos, al igual que chinos, se han convertido en expertos de la manipulación pública en numerosas contiendas políticas alrededor del mundo ${ }^{25}$, y la reacción por parte de muchos gobiernos y organizaciones internacionales no se ha hecho esperar ${ }^{26}$.

Efectivamente, esos discursos e informaciones manipuladas que faltan a la veracidad de los flujos informativos pueden tener tal repercusión en la opinión pública, desestabilizar gobiernos, influir en unas elecciones o poner en riesgo la seguridad, que tanto en el ámbito nacional como supranacional se han propuesto diversas medidas para lucha contra el fenómeno. La ONU expresó en 2017 su preocupación por el tema en la Declaración conjunta sobre Libertad de Expresión y

24 Sustein, Cass R., «How Facebook makes us dumber», Bloomberg, 8/01/2016.

25 Así, también se ha acusado a Rusia de hacer circular una falsa narrativa para justificar sus acciones ilegales en Ucrania. Esta, entre muchos ámbitos más. Una breve descripción de ello puede verse en BONET, Pilar, «La fábrica rusa de las mentiras», El País, 25/02/2018.

26 Además, de las reacciones frente a la intrusión de las noticias rusas en procesos electorales en marcha a lo largo de estos últimos años, en la UE se creó la plataforma $E U$ vs disinfo, que es un proyecto del Servicio Europeo de Acción Exterior que desde 2015 trabaja para dar respuesta a las campañas de desinformación que llegan desde Rusia y afectan a la Unión Europea en su conjunto, a los estados que la forman o a otros países europeos. En las Conclusiones del Consejo de la UE de 10 de diciembre de 2019 sobre «Acciones complementarias para aumentar la resiliencia y luchar contra las amenazas híbridas» (14972/19) hacía de nuevo hincapié en la necesidad de trabajar en contrarrestar la desinformación, detectar las actividades de desinformación de los agentes estatales extranjeros y de los agentes externos no estatales y garantizar unas elecciones libres y justas, que no se vean influenciadas por esas injerencias manipuladoras. 
Noticias Falsas, Desinformación y Propaganda (3 de mayo de 2017). La Unión Europea en 2018 aprobó un Plan de Acción contra la desinformación ${ }^{27}$ y recientemente la Comisión Europea, en la nueva Estrategia de Seguridad de la Unión (24 de junio de 2020) hacía hincapié en la lucha contra «las campañas de desinformación y la radicalización de la narrativa política» ${ }^{28}$. En la misma línea han actuado diferentes Estados. Por concretar en España, ha de recordarse que en la Estrategia de Seguridad Nacional de 2017 ya se citaba la desinformación como una de las amenazas para la seguridad, y la Directiva de Defensa Nacional (DSN), adoptada el 11 de junio de 2020, fijaba también entre los grandes objetivos de defensa el uso de instrumentos para luchar contra esas técnicas manipulativas que utilizan las mentiras con un propósito determinado causando un perjuicio colectivo. Recientemente, con el objetivo de responder a dicho fenómeno se daba a conocer la Orden PCM/1030/2020, de 30 de octubre, por la que se publica el Procedimiento de actuación contra la desinformación aprobado por el Consejo de Seguridad Nacional. Se trata de una disposición que busca dar cumplimiento a las previsiones supranacionales y parte precisamente de señalar que «el acceso a información veraz y diversa es uno de los pilares que sustentan a las sociedades democráticas y que deben asegurar las instituciones y administraciones públicas, porque se conforma como el instrumento que permite a los ciudadanos formarse una opinión sobre los distintos asuntos políticos y sociales». Con posterioridad nos referiremos a estas disposiciones.

\section{LA COMPLICADA DETERMINACIÓN DE LO QUE ES VERDAD Y LO QUE ES MENTIRA}

Se venía hablado más arriba de verdades a medias, de manipulación de la verdad, de mentiras o de hechos/noticias falsas, que vienen a referir todos ellos a algo que hace mella en la verdad. Por lo tanto, conviene detenernos mínimamente en este concepto, el de verdad.

Este no encuentra un significado en el diccionario de la Real Academia Española (RAE) que pueda ofrecer mucha luz a los efectos descubrir fácilmente qué es eso de verdad. Una de sus acepciones habla de «juicio o proposición que no se puede negar racionalmente». Desde esta vertiente, podría entenderse que verdad es algo que siempre va referido a las afirmaciones o juicios de hecho, pues se ha

27 Más recientemente, un informe del Servicio Exterior de la UE destacaba como China y Rusia están difundiendo masivamente información falsa y datos tergiversados en Internet, en esta ocasión sobre el Covid19, con el objetivo de debilitar a la Unión Europea. Así se recoge en el EEAS special report update: short assessment of narratives and disinformation around the covid-19 pandemic, 20-27/03/2020. De hecho, la Comisión Europea abrió una página web para mitigar la desinformación que sufren los ciudadanos respecto al coronavirus con información falsa o «fake news» proveniente de Rusia, China y la derecha de Estados Unidos. Lo mismo ha hecho Naciones Unidas con la iniciativa Verified.

28 EU Security Union Strategy, adoptada por la Comisión Europea para el periodo de 2020-2025. 
entendido que solo estos pueden juzgarse verdaderos o falsos ${ }^{29}$, en contraposición a los juicios de valor donde no es fácil demostrar que están equivocados. Sin embargo, la RAE también define verdad como «conformidad de las cosas con el concepto que de ellas forma la mente» o «conformidad de lo que se dice con lo que se siente o se piensa» o «cualidad de veraz». Lo cual parece conducirnos a algo que no es unívoco y, por lo tanto, a la existencia de verdades que no son iguales y que pueden depender de cada persona o colectivo. Ello por no entrar ahora en algo en lo que nos detendremos posteriormente, que es el consabido tema de que la veracidad no significa verdad absoluta ${ }^{30}$.

Frente a la verdad se han encontrado posiciones de lo más diversas, desde el escepticismo, al relativismo, o a esa convicción muy extendida que considera que sí existe una verdad (o si se quiere, veracidad) común — con independencia de diferencias culturales, religiosas o políticas - sobre un elenco amplio de hechos que son incontrovertibles. Esa pluralidad de posiciones sobre la verdad es descrita por Vives Antón, haciendo un recorrido desde Descartes a la actualidad, poniendo de relieve, además, que la «verdad» no tiene un significado invariable en todos y cada uno de sus diferentes usos. Se puede aludir a la verdad sobre los hechos, pero también a la verdad del Derecho, esto es, a la certeza objetiva de que se está siguiendo la regla pautada en la ley —aquí la verdad equivaldría a seguridad, a certeza, y se predicaría sólo de aquellos enunciados de los que no se puede normalmente dudar, porque están más allá de toda duda razonable_- ${ }^{31}$. Igualmente, la verdad es predicable en otros ámbitos. Tomás Vives recuerda, por ejemplo, cómo hay quienes aluden a la verdad de ciertas creencias, cuando en realidad lo que se quiere decir es que estas están «racionalmente» justificadas ${ }^{32}$.

En el ámbito del Derecho, encontramos diversas normas que sí aluden expresamente al término «verdad» (o a su antónimo, la falsedad). La verdad parece convertirse en no pocas ocasiones en algo necesario para la aplicación del Derecho, porque resulta importante la fijación de unos hechos o elementos procesalmente incontrovertibles. Así sucede en el Código civil cuando refiere a la expresión de causas falsas de la institución de heredero (art. 767 CCiv) o en los contratos (art. 1276 CCiv), al verdadero dueño (art. 1771 Cciv) o el verdadero deudor (art. 1899 Cciv), por poner algunos ejemplos. También el Código Penal

29 Gladio, G., «Derecho Constitucional y tutela de la verdad», AFDUC, n. ${ }^{\circ}$ 16, 2012, p. 394.

30 Recuérdese ahora una de las primeras sentencias del Tribunal Constitucional español a este respecto, la STC 6/1988, de 21 de enero, reiterada con el tiempo en otras tantas sentencias posteriores (las SSTC 190/1996, de 25 de noviembre; 51/1997, de 11 de marzo; 134/1999, de15 de julio; 52/2002, de 25 de febrero; 226/2005, de 24 de octubre; 216/2006, de 3 de julio; 51/2008, de 14 de abril ...) Puede verse también Pauner Chulvi, C., Derecho de la información, Valencia, Tirant lo Blanch, 2014, particularmente pp. 67-78. CARRILlo, M., «Derecho a la información y veracidad informativa (Comentario a las SSTC 168/86 y 6/88)», REDC, n. ${ }^{\circ} 23,1988$, pp. 187-206.

31 Vives Antón, T., «Proceso y verdad: más allá de toda duda razonable», Fundamentos del Sistema Penal, Valencia, Tirant lo Blanch, 2011, p. 960.

32 Ibidem, p. 938. 
exige la declaración de la verdad en el ámbito de un proceso, castigándose el falso testimonio (art. $458 \mathrm{CP}$ ) o habla de la falta a la verdad maliciosa de los peritos o intérpretes (art. 459 y $460 \mathrm{CP}$ ). Asimismo, se castigan las falsedades en documento público, a los funcionarios que faltaren a la verdad en la narración de los hechos (art. $390 \mathrm{CP}$ ), se recoge el delito de denuncias falsas (art. $456 \mathrm{CP}$ ), se impone una sanción al que estando convocado ante una comisión parlamentaria de investigación faltare a la verdad en su testimonio (art. $502 \mathrm{CP}$ ), se castiga la imputación de un delito «hecha con el conocimiento de su falsedad $o$ temerario desprecio hacia la verdad» (art. $205 \mathrm{CP}$ ), y una referencia similar se utiliza en el art. 208 respecto de las injurias.

Por lo tanto, parece que sí hay hechos que, conforme a determinados parámetros, cabe entenderlos como verdaderos y, como consecuencia, las afirmaciones contrarias a tales verdades, en determinados contextos, pueden ser merecedoras de una sanción. Hay un marco definido legalmente en el que ciertas afirmaciones no caben. Esto es, algunas mentiras no son permisibles. Pero, en el debate abierto (de carácter político) ¿ello también es así? ¿También hay mentiras inadmisibles? ¿O todo es más laxo en el debate público, abierto y plural que se pretende en democracia? A ello quisiera referirme más adelante en este trabajo.

Pero, antes de ello, y como contrapunto a la verdad y de cara a fijar los términos empleados en este ensayo, debemos distinguir entre (a) la ocultación explícita de hechos o datos, (b) la falsedad y (c) la mentira o destrucción sistemática de la verdad, siendo esta última la que más daño puede producir, elementos todos ellos que podríamos incluir en lo que comúnmente conocemos como desinformación.

a) El primero de los comportamientos haría referencia precisamente a eso, a la voluntad de evitar el conocimiento de determinados hechos con el interés de crear un relato público distinto o evitar responsabilidades negativas, o incluso con propósitos amparables en el ordenamiento. Esta ha constituido la más tradicional de las mentiras políticas (en sentido amplio del término mentira). Esa ocultación de la verdad ha venido tradicionalmente muy ligada a las políticas gubernamentales relacionadas con la diplomacia, la seguridad o los secretos de Estado, o al menos se han servido de estos ámbitos para la ocultación intencionada de hechos.

La historia nos ha dado sobrados ejemplos. Esta forma de proceder parece haber sido más marcada en los regímenes de tendencia autoritaria, donde la ausencia de mecanismos de control parlamentario, o de cualquier otro tipo, ha facilitado que ello sea así y que este tipo de actuaciones queden indemnes ${ }^{33}$. Pero, también gobiernos democráticos han optado por el uso

33 De igual modo, una de las principales batallas políticas de los regímenes en transición a la democracia, tiene que ver con el descubrimiento de la verdad. Con una lucha contra la falsificación del pasado, que haría imposible en la vida práctica la reconciliación entre los ciudadanos 
de medio-verdades o la ocultación de la verdad. Podemos recordar ahora desde las «mentiras» desveladas por los Papeles del Pentágono sobre la actuación de EEUU en Vietnam, hasta el recurso de este mismo país (y algunos otros) a la idea de que Irak escondía armas de destrucción masiva para justificar una guerra, cuando el tiempo demostró que Irak no poseía tal arsenal. $\mathrm{O}$ bien, las informaciones que se dieron los primeros días por parte del Gobierno español sobre la autoridad de los atentados terroristas yihadistas del 11 de marzo de 2004 en Madrid, insinuando que los autores parecían pertenecer a la banda terrorista ETA. Por supuesto, podríamos citar innumerables muestras más y todas muy diversas. No son pocas las «mentiras» o las verdades ocultas por los gobiernos que, con el paso del tiempo, la historia ha sacado a la luz pública.

Hannah Arendt señalaba que «El secretismo — denominado diplomáticamente discreción, así como arcana imperii, los misterios del gobiernoy el engaño, es decir, la deliberada falsedad y la pura mentira como medios legítimos para el logro de fines políticos, nos han acompañado desde el comienzo de la historia escrita» ${ }^{34}$. En definitiva, los gobernantes siempre han conseguido, con mayor o menor éxito, obrar sobre sus verdades mediante la destrucción o sustitución de datos. Eso es algo que sigue sucediendo hoy. E insistimos, no solo lo hacen los gobiernos, sino también cualquier grupo de interés, partido, o movimiento político que trata de influir en el debate político.

b) La falsedad es el recurso a instrumentos que crean una apariencia pretendida de algo que no es cierto, se acerca un poco más a la estrategia, al simulacro, puede incluso encajar con medias verdades. Maquiavelo en su obra El Principe describe bien el recurso a las falsedades, - a las apariencias-, como una necesidad política y el saber mentir - la simulacióncomo una virtud de quien gobierna. Recordemos ahora las palabras: «Todos ven lo que pareces, pero pocos comprenden lo que eres (...) Procure, pues un príncipe conservar y mantener el Estado: los medios que emplee serán siempre considerados honrosos y alabados por todos; porque el vulgo se deja siempre coger por las apariencias (...) Un príncipe de nuestros tiempos jamás predica otra cosa que paz y lealtad, y en cambio es enemigo acérrimo de una y otra $»^{35}$.

Se trata de crear un relato que favorezca a quien trata de transmitir una idea o una información con la intención de influir en la opinión pública.

c) Por último, la mentira opera una destrucción radical de la verdad a sabiendas de ello. La mentira falta intencional y conscientemente a la verdad afirmando como verdaderos hechos que no son de ningún modo

34 Arendt, H., «La mentira en política», Verdad y mentira en la política, op. cit, p. 87.

35 Maquiavelo, El Príncipe, Barcelona, Bruguera, 1981, pp. 152-153. 
ciertos, creando una «realidad» ficticia con el propósito de engañar ${ }^{36}$. Las mentiras serían aquí sinónimo del concepto muy extendido en nuestros días de bulos, o fake news en su expresión inglesa.

Todas estas figuras pueden perseguir intereses de lo más dispar: la voluntad de no inculpar a alguien de unos hechos, eximirse de la propia culpa, la obtención de un rédito económico, el puro propósito de hacer daño a un tercero, la voluntad de generar descrédito sobre una persona, un colectivo, un partido político o el gobierno, el deseo de convencer a la opinión pública sobre un ideario religioso o ideológico, la aspiración a obtener un apoyo político del electorado, la pretensión de mantenerse en el poder, o el intento de crearse una imagen pública, entre otras razones.

Centrémonos en la verdad y la falsedad/mentira en el debate público hoy, en aquellas afirmaciones no veraces que tienen una intencionalidad política. Me gustaría ocuparme de la transmisión pública de hechos no veraces o de ideas con una base fáctica falaz, que buscan influir en la opinión pública.

\section{LA COMPLEJA DISOCIACIÓN ENTRE HECHOS Y OPINIONES. LA VERACIDAD SOBRE LOS HECHOS Y LOS LÍMITES A LAS OPINIONES}

La doctrina ha destacado que la «verdad única» no existe. Desde luego, no existe sobre las opiniones, ya que el pluralismo implica la aceptación de una diferente visión de análisis de la realidad social. Las opiniones, los juicios de valor, las ideas, los pareceres personales, los pensamientos, las creencias y su libre expresión constituyen la base de ese pluralismo que nuestra Constitución toma como valor principal del Estado. De hecho, cuando se alardea de una única verdad oficial, de lo indiscutible de determinadas afirmaciones, flaco favor se está haciendo a la democracia y, por tanto, al pluralismo. Recordaba Villaverde Menéndez que la Constitución, en hipótesis, está para que nadie tenga el poder de decidir qué es verdad y qué no lo es, ni siquiera ella misma ${ }^{37}$.

Cuando se transmiten opiniones, cuando se ejerce la libertad de expresión, la componente valorativa de quien la ejerce tiene un alcance muy significativo ${ }^{38}$. La expresión de las ideas constituye una materialización de la propia libertad, que es subjetiva, la libertad de pensamiento. Ahora bien, como ha señalado el Tribunal Constitucional, esa libertad de expresión no es absoluta. Así, el Tribunal recordó desde los inicios que la libertad para expresar opiniones no comprende la posibilidad

36 Dice la RAE que mentir es «Decir o manifestar lo contrario de lo que se sabe, cree o piensa».

37 Villaverde Menéndez, I., «Verdad y Constitución...», op. cit., p. 153.

38 Carrillo, M., «Expresión e información: dos derechos entre la sociedad y el Estado», Autonomies, n. ${ }^{\circ} 21,1996$, p. 179 
de ejercer sobre terceros una violencia moral, porque ello es contrario a bienes jurídicos constitucionalmente protegidos, como son la dignidad de la persona y su derecho a la integridad moral, recogidos en los arts. 10 y 15 de la CE (STC 2/1982, de 29 de enero, FJ 5), o los derechos de la personalidad (art. 18 CE). Ello implica que la exteriorización de ideas puede encontrar un límite en el daño que puedan generar en derechos de otros individuos.

La otra cuestión que cabe preguntarse es si cabe también la limitación de expresiones (de opiniones) que violentan los valores y principios más básicos de nuestro ordenamiento de un modo más abstracto. A este respecto, es cierto que el Tribunal Constitucional ha reconocido que, al resguardo de la libertad de opinión, cabe cualquier idea, por equivocada o peligrosa que pueda parecer al lector, incluso las que ataquen al propio sistema democrático. Pero, al mismo tiempo, ha señalado que la libertad de expresión no puede amparar manifestaciones o expresiones destinadas a menospreciar o a generar sentimientos de hostilidad contra determinados grupos étnicos, de extranjeros o inmigrantes, religiosos o sociales en un Estado como el español, social, democrático y de Derecho. Ha indicado que no puede amparar una actitud racista por contrariar al conjunto de valores protegidos constitucionalmente (STC 176/1995, de 12 de enero).

Precisamente en un contexto de manifestaciones contrarias a la verdad histórica incontrovertible como es la del Holocausto del pueblo judío, el Tribunal ya había señalado que esto no quiere decir que uno no pueda entender la Historia como desee; o construir una verdad histórica propia y creer lo que más le plazca, contarlo y defenderlo públicamente, e incluso hacerlo maliciosamente, lo que no puede hacerse es usar esa «verdad singular» para atentar contra la dignidad de otros (STS 214/1991, de 11 de noviembre). El Tribunal vino a decir que ello «sería tanto como admitir que, por el mero hecho de efectuarse al hilo de un discurso más o menos histórico, la Constitución permite la violación de uno de los valores superiores del ordenamiento jurídico, como es la igualdad (art. 1.1 CE) y uno de los fundamentos del orden político y de la paz social: la dignidad de la persona (art. 10.1 CE)» (STC 214/1991, FJ 8).

En un caso posterior, en la cuestión de inconstitucionalidad que se resolvió por STC 235/2007, sobre la sanción penal de la negación de cualquiera de las distintas formas de genocidio recogidas en el art. $607.2 \mathrm{CP}^{39}$, el Alto Tribunal afrontaría la cuestión claramente desde la perspectiva de si caben opiniones contrarias al propio sistema constitucional. El Tribunal se decantó mayoritariamente por un modelo en el que no cabe la «democracia militante», como sí ocurre en Alemania, pero el fallo suscitó un confrontado debate en su seno. De hecho, el mismo se aprobó con cuatro votos discrepantes, lo cual es muy significativo.

39 Cuestión de inconstitucionalidad número 5152-2000, promovida por la Audiencia Provincial de Barcelona en relación con el artículo 607.2 del Código penal, por presunta violación del artículo 20.1 de la Constitución. 
Nuevamente advirtió que la libertad de expresión no puede verse restringida por el hecho de que se utilice para la difusión de ideas contrarias a la propia Constitución, pero añadió: a no ser que con ellas se lesionen efectivamente derechos o bienes de relevancia constitucional. Los votos discrepantes, que incidieron en las decisiones adoptadas en el marco de la UE y del Consejo de Europa sobre la necesidad de no dar cobijo en los ordenamientos a ideas xenófobas que puedan hacer crecer en la opinión pública el rechazo hacia determinados colectivos, entendieron que las actitudes negacionistas van encaminadas a hacer surgir estados de opinión tergiversados (en aquella ocasión sobre el hecho histórico del Holocausto). Prohibiendo tal tipo de afirmaciones se trata de proteger a la sociedad de aquellos comportamientos contrarios a una realidad que existió. Los magistrados discrepantes entendieron que son afirmaciones que, de reiterarse, a través de medios propagandísticos, pueden generar un clima de violencia y hostilidad hacia determinadas minorías, un peligro que la sociedad democrática no puede permitirse correr. Decía el magistrado Rodríguez Arribas en su voto discrepante: «No se trata de favorecer la fórmula de una democracia militante, pero sí de impedir la conversión de las instituciones que garantizan la libertad en una democracia ingenua que llevara aquel supremo valor de la convivencia hasta el extremo de permitir la actuación impune de quienes pretenden secuestrarla o destruirla».

Los votos particulares señalan también la dignidad de la persona, como fundamento del sistema de derechos, como razón para limitar ciertas expresiones negacionistas. Incluso uno de los magistrados (de nuevo Ramón Rodríguez Arribas) entendió que la misma negación de una realidad incontestable como la del Holocausto ya constituye un claro menosprecio hacia las víctimas que lo sufrieron. En una línea similar, el TEDH al enfrentarse a los casos de sanción del negacionismo no ha acudido al cano de la libertad de expresión, sino al del abuso del Derecho donde las opiniones negacionistas se confrontan con verdades incontrovertibles $^{40}$.

Cosa distinta de las ideas u opiniones sobre los hechos son los hechos mismos. Así, mientras las ideas, pensamientos y opiniones constituyen el objeto de la libertad de expresión, los hechos lo son principalmente de la libertad informativa. Cuando hablamos de hechos nos referimos a elementos fácticos. Decíamos que la verdad única no existe sobre las opiniones, pero, incluso sobre los hechos también se ha señalado que un mismo hecho no pocas veces puede ser explicado de diversas y plurales maneras, en un ejercicio de la libertad informativa, dejando patente que todas esas formas son veraces ${ }^{41}$. Ante un mismo hecho pueden existir diversos criterios de interpretación y de explicación. De todos modos, aunque la

40 Sobre ello puede verse el trabajo de Bilbao Ubillos, J.M., «La negación del Holocausto en la jurisprudencia del Tribunal Europeo de Derechos Humanos: la endeble justificación de tipos penales contrarios a la libertad de expresión», RDP, n. ${ }^{\circ} 71-72,2008$, pp. 19-56.

41 De Carreras Serra, L., Régimen jurídico de la información. Periodistas y medios de comunicación, Ariel Derecho, Barcelona, 1996, p. 47. 
«verdad» puede ser interpretable en muchas ocasiones, también es cierto que el término verdad siempre alude a una cierta certeza.

Por todo ello, tal vez sea más importante incidir en el concepto de veracidad más que en el de verdad única o verdad absoluta. Recordemos que la Constitución española, no alude al término «verdad», sino que reconoce en el art. 20 el derecho a comunicar o recibir libremente información veraz.

Así, la verdad (o veracidad) ha venido referida fundamentalmente a la transmisión de hechos y, por lo tanto, al ejercicio del derecho a la información como fundamento básico de cualquier democracia. Esa trascendencia constitucional del derecho de información exige a la persona que haya divulgado los hechos noticiables una actitud positiva hacia la verdad, de manera que se pueda probar que ha tratado de encontrarla agotando los medios disponibles ${ }^{42}$; hablamos del requisito de buena fe, de la convicción de que se está proporcionando una información veraz (STEDH Gasior vs. Polonia, de 21 de febrero de 2012). Si esta actitud de diligencia se da, aunque la información no sea totalmente exacta, quedaría protegida por la Constitución ${ }^{43}$. Esta idea fue introducida por el Tribunal Supremo norteamericano en el caso New York Times c. Sullivan ${ }^{44}$, al que me referiré posteriormente con más detenimiento, $y$ acogida por nuestro Tribunal Constitucional ${ }^{45}$. Este último ha declarado reiteradamente que la veracidad no va dirigida a la exigencia de una rigurosa y total exactitud en el contenido de la información, sino a negar la protección constitucional a los que transmiten como hechos verdaderos bien simples rumores, carentes de toda constatación, bien meras invenciones o insinuaciones, sin comprobar su realidad mediante las oportunas averiguaciones propias de un profesional diligente; así, una información se considerará veraz aunque su total exactitud pueda ser controvertida, o se incurra en errores circunstanciales o resulte una información incompleta que, en un caso u otro, no afecten a la esencia de lo informado. Por lo tanto, en el marco de la transmisión de información, esa veracidad exigirá una actuación diligente que lleve al que transmite el hecho noticiable a realizar una labor de verificación, de comprobación/contrastación de los datos, y para ello se tendrá en cuenta no solo esa diligencia, sino también otros elementos como el carácter del hecho noticioso, la fuente que proporciona la información, o el posible daño que esa información pueda generar en los derechos de terceros ${ }^{46}$. Lo cual significa que donde hay libertad informativa cabe el error. En todo caso, lo

42 Villaverde Menéndez, I., «La libertad de expresión. Comentario al art. 20.1 CE», Casas/Rodríguez-Piñero (dirs.), Comentarios a la Constitución española (XXX Aniversario), Madrid: Kluwer, Tribunal Constitucional, 2008, pp. 471 y ss.

43 MuÑoz Machado, S., Libertad de prensa y procesos por difamación, Editorial Ariel, Barcelona, 1988, pp. 154-155. Véase también Rallo Lombarte, A., Pluralismo informativo y Constitución, Valencia, Tirant lo Blanch, 2000.

44 Caso New York times c. Sullivan (376 U.S. 254 1964).

45 SSTC 6/1988, 107/1988, 105/1990, 171/1990 y 172/1990, 40/1992, 192/1999.

46 Esa idea de veracidad ampliamente desarrollada por nuestro Tribunal Constitucional. Entre muchas otras, SSTC 41/1994, de 15 de febrero, o 158/2003, de 15 de septiembre. 
que queda claro, a los efectos de lo que venimos analizando en este trabajo, es que lo que no protege el art. 20.1.d) de la Constitución es la insidia, el engaño por negligencia o la mala intención.

En todo caso, las cosas son aún más complejas. Al igual que decíamos que no existe una verdad única en democracia, también es cierto que la trasmisión de hechos noticiables exenta de todo posicionamiento ideológico es difícil. Recordemos la dificultad de separar el ejercicio de la libertad informativa del de la libertad de expresión y opinión ${ }^{47}$. Hay hechos que transmitidos desde una cierta perspectiva ideológica dan lugar a una verdad determinada y asumida colectivamente como cierta. Pero, esos mismos hechos, contados de otro modo, pueden conducir a una verdad opuesta. Incluso la historia se escribe con verdades que resultan de una forma de asumir unos hechos desde una perspectiva. Aún así, decía Hannah Arendt que «cuando admitimos que cada generación tiene derecho a escribir su propia historia, solo estamos reconociendo el derecho a ordenar los acontecimientos según la perspectiva de dicha generación, no el derecho a alterar el propio asunto objetivo ${ }^{48}$. A este respecto, contaba que cuando Clemenceau mantuvo una conversación amistosa con un representante de la República de Weimar sobre la cuestión de la culpa del estallido de la Primera Guerra Mundial, se le preguntó qué pensarían los futuros historiadores acerca de ese asunto tan controvertido y el respondió: «no lo sé, pero estoy seguro de que no dirán que Bélgica invadió Alemania» ${ }^{49}$.

Pero, que unas creencias o unos pensamientos puedan estar racionalmente justificados no los convierte en verdaderos, como no podemos decir que hay ideas falsas. Lo que sí es más fácil es la determinación de la verdad o falsedad de los hechos que sustentan determinadas ideas o afirmaciones.

$\mathrm{Y}$ es que a veces nos movemos en ese ámbito que queda a medio camino entre la libertad de información y la libertad de expresión, porque los hechos (propios del ejercicio de la libertad informativa) se cuentan o se transmiten con una marcada visión ideológica (lo que es propio del ejercicio de la libertad de opinión y expresión). Esto es importante porque, aunque la veracidad no constituye un límite a las libertades ideológicas o de expresión, como se recordaba más arriba, estas no son libertades absolutas. En esta confluencia entre libertad de expresión y libertad de información, entre opiniones y hechos, conviene volver de nuevo la doctrina del Tribunal Supremo norteamericano sobre los límites a la libertad de expresión y su test de la «real malice (actual malice)», que empezó a

47 La libertad de expresión, en sentido estricto, y el derecho a comunicar y recibir información veraz se diferencian fundamentalmente, por su objeto. García Guerrero, J.L, «Una visión de la libertad de comunicación desde la perspectiva de las diferencias entre la libertad de expresión, en sentido estricto, y la libertad de información», TRC, n. ${ }^{\circ}$ 20, 2007, pp. 359-399. El Tribunal Constitucional, en la STC 47/2000, establecía la diferencia: mientras la primera «tienen por objeto pensamientos, ideas y opiniones, en un concepto amplio, el derecho de información versa, en cambio, sobre hechos» (STC 61/1988).

48 Arendt, H., «Verdad y política», op. cit., p. 36.

49 Ibidem. 
aplicarse a partir del caso New York Times c. Sullivan. La cuestión que se planteó es si las opiniones expresadas en un periódico perdían protección debido a la falsedad de alguna de las afirmaciones sobre hechos y la pretendida voluntad de difamar. El tribunal concluyó que las manifestaciones inexactas e incluso intencionadas quedan amparadas en la libertad de expresión, a no ser que se compruebe que las afirmaciones son realizadas con «real malicia», es decir, con conocimiento de que los hechos transmitidos son falsos o con una temeraria despreocupación acerca de su verdad o falsedad. Esta postura doctrinal resulta fundamental para lo que pretendemos defender en este trabajo. Ello significa que la libertad de expresión no debería poder amparar aquellas posturas u opiniones que se transmiten sustentándose en hechos intencionadamente falsos. El test que introducía el Supremo norteamericano no lo superarían los casos en los que se vierten opiniones sustentadas en hechos falaces, esto es, con el conocimiento de que estos no son ciertos — son mentira-, o con conocimiento de su posible falsedad o sin base probatoria o indagatoria previa alguna sobre los mismos. Insisto, no se está diciendo que puedan existir ideas falsas, sino que no hay protección constitucional para expresiones falsas sobre los hechos.

Por supuesto, de nuevo la dificultad se encuentra en determinar si estamos ante una afirmación de hechos o tan solo frente a una expresión de opiniones ${ }^{50}$. Para discernirlo, pueden tenerse en cuenta varios factores: los términos utilizados, que puedan hacer entender al lector medio que se trata de la transmisión de unos hechos y no de una manifestación de opinión; la verificabilidad; o el contexto en el que la manifestación se produce. Aún así no siempre resulta fácil.

Lo principal es establecer, por un lado, qué se está protegido constitucionalmente en la transmisión de hechos y de opiniones y, por otro lado, qué mensajes pueden caer en el lado de lo prohibido, en el de las manifestaciones que incluso pueden ser perseguibles penalmente porque, realizándose con un temerario desprecio a la verdad, causan un daño. Ello puede producirse cuando esa transmisión de hechos, — sea en el ejercicio de la libertad de información o acompañando a una expresión del pensamiento_-, entra en colisión otros derechos o intereses constitucionalmente protegidos. Porque, como recordaba Vives Antón, sólo se puede castigar (y solo se puede exigir responsabilidad civil) allí donde haya una lesión o puesta en peligro de un bien jurídico ${ }^{51}$. No toda afirmación o discurso que repugne al colectivo mayoritario de la población o parezca poner en peligro los principios básicos de nuestro ordenamiento ha de ser censurado, por supuesto. No se trata de que las ideas no sean inocuas, sino de que el ejercicio de algunas libertades — como las de expresión o información-, aunque parezca que generan un peligro abstracto, no pueden combatirse siempre por medio de la restricción

$50 \mathrm{El} \mathrm{TC}$ ha insistido en la necesidad de ello al recordar que mientras los hechos son susceptibles de prueba, las opiniones o juicios de valor, por su misma naturaleza, no se prestan a una demostración de exactitud. (STC 79/2014, de 28 de mayo).

51 Vives Antón, T., Fundamentos del Sistema Penal, op. cit., p. 667. 
de tales libertades, habrá que analizar, caso por caso, si pueden producir un daño concreto a algún valor del Estado o bien colectivo. En esto, Rawls criticaba la aplicación al discurso político de la conocida regla del Tribunal Supremo norteamericano sobre el «peligro claro y presente» como limitativo de la libertad de expresión. Rawls lo estima «una base insatisfactoria para la protección constitucional del discurso político, pues lleva a centrarse en la peligrosidad del discurso en cuestión, como si por el hecho de ser peligroso el discurso se convirtiese en un delito» ${ }^{52}$. Tal vez en algunos ámbitos la libertad haya de defenderse por sí misma, esto es, sin ayuda de la coacción estatal ${ }^{53}$. Pero, en otras ocasiones, sí es necesario adoptar medidas contra expresiones o discursos políticos porque efectivamente dañan o ponen en peligro bienes protegidos en el ordenamiento, y más aún cuando realmente en el fondo no constituyen un ejercicio de la libertad ideológica, sino más bien la transmisión de una información falsa (disfrazada de idea), y esto no tiene cobertura constitucional.

\section{V. ¿CABEN LOS MENSAJES QUE, FALTANDO A LA VERDAD, VIOLENTAN LOS VALORES Y PRINCIPIOS BÁSICOS DE NUESTRO ORDENAMIENTO?}

Los textos Constitucionales vienen a establecer ciertos elementos como fundamentales para la convivencia de un Estado. Estos, que reciben el nombre de principios o valores fundamentales, tienden a considerarse como condición sine qua non para el ejercicio del poder y de los derechos a los que alude la Carta magna, constituyen los elementos definitorios de un Estado.

Precisamente, en los orígenes del Constitucionalismo se recurrió al término verdades para referirse a los mismos. Así, la Declaración de independencia norteamericana (1776) recogía en sus primeros párrafos: «Sostenemos como evidentes estas verdades: que los hombres son creados iguales; que son dotados por su Creador de ciertos derechos inalienables; que entre estos están la vida, la libertad y la búsqueda de la felicidad». Esta constituyó una declaración de principios a través de la cual debía interpretarse la Constitución de los Estados Unidos. El texto inspiró muchos otros documentos similares en otros países y pocas son las Constituciones que, aún sin utilizar el término verdades, sí aluden a principios o valores esenciales del Estado constitucional que vienen a actuar no solo como reglas interpretativas del propio texto, sino también como orientación y límite al ejercicio del poder y del disfrute de los derechos fundamentales.

De hecho, todas las sociedades democráticas, pese a su compromiso general con la libertad de expresión y las libertades informativas, han reprimido reiteradamente

52 Rawls, J., Sobre las libertades, Paidós, Barcelona, 1996, p. 98.

53 Vives Antón, T., Fundamentos..., op. cit., p. 822. 
ciertas formas de discurso, alegando que representaban un peligro para otros valores u objetivos sociales básicos. Tradicionalmente en nombre de la seguridad, o de la protección de los derechos de terceros o de la sociedad frente a la amenaza de ciertos mensajes, se ha prohibido el libelo sedicioso, la defensa de ideas políticas extremas (en el pasado el comunismo o los fascismos, hoy las provenientes de ciertos partidos de extrema derecha o izquierda), y más recientemente, las expresiones que pueden dañar la dignidad individuos o colectivos sobre la base de su raza, religión, sexo, u orientación sexual. Como se preguntaba Rodríguez Montañés, «¿En qué punto, si es que en alguno, la crítica política o social se convierte en tan extrema u ofensiva para las normas sociales básicas o es tan desgarradora de los objetivos sociales que puede ser legítimamente suprimida en una sociedad democrática?» ${ }^{54}$. A lo que añadiríamos, ¿y dónde se encuentra ese punto de inflexión si, además, esa crítica política pivota sobre afirmaciones factuales que de algún modo faltan a la verdad? A día de hoy, el mentir — las fakes — no son delito, como tal, aunque existen figuras penales que podrían cubrir el daño que las mismas pueden generar en determinados bienes jurídicos protegidos (delitos de odio o de discurso del odio, injurias, calumnias, desórdenes públicos, delitos contra la integridad moral, la salud pública o contra el mercado y los consumidores) $)^{55}$.

Aludimos ahora a ello porque, en el marco general de la desinformación, la retórica de algunos movimientos o partidos políticos ha hecho uso de afirmaciones falsas que no solo rompen con las reglas de honestidad que debieran regir toda contienda democrática, sino que, además, violentan esos valores y principios fundamentales. Una muestra de esto lo constituyeron los fascismos en el pasado y hoy lo son algunos populismos y partidos de ideología extrema. No son pocos autores los que alertan del peligro que supone para la propia existencia de la democracia el resurgir de movimientos y actitudes que se consideran y se muestran abiertamente beligerantes contra las propias democracias y las sociedades abiertas que éstas han venido desarrollando en los últimos tiempos ${ }^{56}$. Lo que ha caracterizado a muchos de estos movimientos es el buscar el menoscabo de la confianza en las instituciones democráticas, el recurso a las mentiras disfrazadas de verdades en relación a los extranjeros o a los pertenecientes a determinada raza, grupo étnico o religión, la glorificación de la lucha como grupo, o incluso el empeño por revestir de un significado tergiversado los mismos bienes o valores que podemos encontrar en los textos constitucionales como los de justicia, libertad, familia, o nación. Algunos han hecho de determinados discursos de rechazo

54 Rodríguez Montañés, T., Libertad de expresión, discurso extremo y delito. Una aproximación desde la Constitución a las fronteras del derecho penal, Valencia, Tirant lo Blanch, 2012, p. 115.

55 Hay conductas que merecen un reproche social, que queda materializado en la previsión de una sanción penal, por dañar o poner en riesgo derechos o bienes de terceros o de la colectividad (la honorabilidad, la dignidad, el respeto a la igualdad, la seguridad...)

56 Galán Muñoz, A., «Delitos de odio, Discurso del odio y Derecho penal: ¿Hacia la construcción de injustos penales por peligrosidad estructural?», Galán Muñoz, Alfonso y Mendoza Calderón, S., Derecho penal y política criminal en tiempos convulsos, Valencia, Tirant lo Blanch, 2020, p. 62. 
hacia ciertos colectivos su eslogan, lo cual puede ir más allá de la propaganda negativa y la denigración política que muchas veces forma parte de la política-espectáculo y cabe dentro de la libertad ideológica ${ }^{57}$. Así, a modo de ejemplo, el gobierno húngaro participó en campañas de noticias falsas contra los inmigrantes desde $2015^{58}$. En los prolegómenos de las elecciones generales italianas de 2018, el Movimento Cique Stelle y la Lega Nord fueron acusados de estar detrás de páginas webs pretendidamente independientes que fabricaron contenidos y noticias falsas para favorecer sus campañas electorales y muchas de esos mensajes o informaciones concernían a los inmigrantes ${ }^{59}$. Cabe recordar también el caso de Lisa, una niña de 13 años ruso-alemana que desapareció en Alemania y, con un consabido interés, se publicó que había sido violada por inmigrantes musulmanes. El hecho fue desmentido posteriormente por la policía alemana, pero la difusión de la noticia en medios y redes sociales había sido tal que el daño perseguido sobre la comunidad islámica ya se había producido. En Suiza, el EDC/SVP (Unión démocratique du centre/Schwizerische Volkspartei) es conocido por sus programas, campañas y propaganda racistas y xenófobas en ocasiones haciendo uso de la desinformación ${ }^{60}$. En otras áreas del planeta, también han proliferado las noticias falsas sobre determinados colectivos que acaban generando un rechazo masivo sobre los mismos. Por poner solo algunos ejemplos, en marzo de 2017 se produjo en Sri Lanka una oleada de ataques contra la minoría musulmana del país después de que se difundieran falsas noticias sobre ataques inventados de los musulmanes contra la población cingalesa, de mayoría budista. Asimismo, las campañas de desinformación contra la comunidad minoritaria de los Rohingya en Myanmar, fueron consideradas parte de lo que Naciones Unidas consideró como un genocidio ${ }^{61}$.

La cuestión es que estas campañas, que han hecho uso de bots y trolls ${ }^{62}$ en las redes sociales para difundir mensajes falsos sobre determinados colectivos, han conseguido captar la atención, incluso el voto, de porcentajes no desdeñables de la población sobre la base de un discurso contrario a sacrosantos principios constitucionales como la igualdad, el pluralismo, o la libertad religiosa. El problema no es nuevo, pero el mundo en red en el que vivimos ha conseguido redimensionarlo.

57 Sobre la denigración política (concepto legal que no existe en España, pero sí en otros países como México) y la propaganda negativa en política puede verse: PÉrez De La Fuente, O., Libertad de expresión y discurso político. Propaganda negativa y neutralidad de los medios en campañas electorales, Valencia, Tirant lo Blanch, 2014.

58 BAYER, J. (Coord., ed.), Disinformation and propaganda..., op. cit., p. 46.

59 Ibidem, p. 47.

60 El partido EDC/SVP es considerado por algunos como de extrema derecho, por otros como de populismo de derecha. Sobre el discurso del odio de este partido puede verse el trabajo de MARTín Herrera, D., «Hate speech y tolerancia religiosa en el sistema helvético de democracia participativa», RDP, n. ${ }^{\circ} 90,2014$, pp. 249-284.

61 Mozur, P., «A Genocide Incited on Facebook, With Posts From Myanmar's Military», The New York Times, 18/10/2018.

62 Aunque es una cuestión que escapa ahora a este trabajo, por limitación de espacio, resulta interesante la lectura de: Pérez Colomé, J., «Yo fui un bot: las confesiones de un agente dedicado al engaño en Twitter», El País, 21/05/2020. 
En España, el discurso de Vox contra la inmigración irregular o los musulmanes también ha sido sonado con recurso a afirmaciones no veraces ${ }^{63}$. En 2019 Vox, a raíz de una publicación en El País sobre la violación de una mujer por cinco individuos, lanzaba un tuit en Vox Noticias en el que acusaba a cinco magrebíes de tal agresión. El Tuit rezaba lo siguiente: «Lo País, se os ha olvidado un detalle, son cinco magrebíes. Imprescindible puntualizar el origen extranjero de la mayoría de los violadores para que los españoles tomen conciencia del tipo de delincuentes a los que estáis abriendo las puertas y subsidiando con el dinero de todos» ${ }^{64}$. Lo lamentable del caso es que, a pesar de que se demostró que todos los detenidos eran españoles, incluso la prensa ya había indicado que eran de esta nacionalidad con anterioridad, la Audiencia Provincial de Valencia acabó desestimando el recurso interpuesto por la Sección de delitos de odio de la Fiscalía de Valencia al enmarcarlo en el ejercicio de la libertad de expresión de un partido político ${ }^{65}$. Para la Sala el mensaje se libró en el ámbito de la libre formación de la opinión pública sobre la regulación de las políticas migratorias.

Los mensajes en las páginas web y en las cuentas de Twitter constituyen una vía más de la expresión de los programas, ideario y opiniones de un partido político en nuestros días, es un canal a través del cual forman (e intentan influir) a la opinión pública y, por lo tanto, cabe enmarcarlos en la libertad de expresión. Ciertamente, el ejercicio de la libertad de expresión o los mensajes de carácter ideológico no vienen limitados por la veracidad, pero, sí por los consabidos límites que dicha libertad presenta (honor, intimidad, propia imagen y derechos de terceros, entre otros, lo que supone que no cabe el derecho al insulto, que no son admisibles manifestaciones que inciten al odio o la discriminación ${ }^{66}$, etc. $)^{67}$. De

63 La Unión Europea puso a este partido como ejemplo de grupo de extrema derecha que utiliza habitualmente la desinformación y propagación de bulos en redes sociales en campaña electoral. «Descubrimos una red coordinada en Twitter, mezcla de bots y cuentas falsas, con el objetivo de impulsar hashtags anti-islam y amplificar apoyo al partido populista de derechas Vox». Así lo aseguró el excomisario europeo de Seguridad, Julian King, durante la presentación en 2019 de la Comunicación de la Comisión Europea sobre los progresos en la lucha contra la desinformación en la UE. ANTQUERA, J., «Los informes de la UE alertan de que Vox propaga bulos en redes sociales para desestabilizar la democracia», Diario 16, 16/04/2020.

64 Numerosos extractos de la decisión judicial ser recogen en Bono, F., «La Audiencia de Valencia enmarca en la libertad de expresión un tuit falso de Vox sobre un abuso sexual», El País, 9/06/2020. Al igual que en Levante-EMV, «La Audiencia ve 'libertad de expresión' en una noticia falsa difundida por Vox», Levante. El Mercantil Valenciano, 10/06/2020. EFE, «La Audiencia de Valencia considera 'libertad de expresión que Vox tuitee que la mayoría de violadores son magrebíes», El Mundo, 10/06/2020.

65 Auto de 9/06/2020.

66 Señalaba el TC, «esos discursos quedan extramuros del ámbito de protección de la libertad de expresión..., que no puede servir de cobertura porque suponen una incitación directa o indirecta a la violencia contra ciudadanos en general, o contra concretos ciudadanos que se hayan situados en determinadas situaciones» (STC 235/2007) Sobre jurisprudencia del TEDH acerca del discurso del odio puede consultarse: TERUEL LozANO, G., «El discurso del odio como límite a la libertad de expresión en el marco del Convenio europeo», RDCE, $\mathrm{n}^{\circ}$ 27, 2017. Rollnert, G., «El discurso del odio y sus límites de libertad de expresión: de la zona intermedia a los estándares internacionales», Miró Llinares, F., (Dir.), Cometer delitos en 140 caracteres. El Derecho penal ante el odio y la radicalización en Internet, Madrid, Marcial Pons, 2017, pp. 255-274.

67 No hace falta más que recordar ahora el apartado 4 del art. 20 CE: «Estas libertades tienen su límite en el respeto a los derechos reconocidos en este Título, en los preceptos de las leyes que lo desarrollen y, 
hecho, la propia Sala de la Audiencia señalaba en su decisión que «la demagogia y los populismos no son censurables desde este punto de vista, con el límite del discurso del odio». A pesar de ello, se decidió sobreseer la causa, lo cual es de lamentar siendo una de las primeras decisiones judiciales sobre fakes.

Discrepo de la decisión adoptada por el tribunal por varias razones. En primer lugar, porque que el ejercicio de la libertad de expresión deba gozar del mayor desarrollo posible, más aún en el marco de un debate político y fundamentalmente cuando es un partido político o un parlamentario el que la ejerce, no significa que todo valga. Es cierto que la trasmisión de hechos falsos no constituye delito en si misma, pero el daño que produce, sea en el ejercicio de la libertad de expresión o de información, si fuera el caso, sí está prohibido en nuestro ordenamiento en determinados supuestos. No todo cabe bajo el manto de protección de la libertad de expresión, ni siquiera en el ámbito del debate político. La transmisión de hechos intencionadamente falsos que causan un daño no puede quedar amparado abiertamente en la libertad de expresión. Así lo ha indicado el TEDH, que excluye de la libertad de expresión la propagación de ideas que inciten, promuevan o justifiquen el odio racial, la xenofobia, el antisemitismo y otras formas de odio basadas en la intolerancia que se manifiesten a través del nacionalismo agresivo y la discriminación y hostilidad contra las minorías inmigrantes (Entre otros, Asunto Feret c. Bélgica, de 16 de julio de 2009) ${ }^{68}$.

Como hemos visto más arriba, el Tribunal Constitucional español recordó que ni el ejercicio de la libertad ideológica ni la de expresión pueden amparar manifestaciones o expresiones destinadas a menospreciar o a generar sentimientos de hostilidad contra determinados grupos étnicos, de extranjeros o inmigrantes, religiosos o sociales, pues en un Estado como el español, social, democrático y de Derecho, los integrantes de aquellas colectividades tienen el derecho a convivir pacíficamente y a ser plenamente respetados por los demás miembros de la comunidad social. Ello no solo puede ser contrario al derecho al honor de las personas directamente afectadas, sino a otros bienes constitucionales como el de la dignidad humana (art. $10 \mathrm{CE})^{69}$. Asimismo, el Tribunal Europeo, aún siendo generoso en el reconocimiento de la extensión de la libertad de expresión en el debate político, incluida «una determinada dosis de exageración, o de incluso de provocación, es decir, a ser un tanto inmoderado en sus observaciones», también ha recordado que no se pueden superar determinados límites, en particular, el respeto de la reputación y los derechos de los otros ${ }^{70}$.

especialmente, en el derecho al honor, a la intimidad, a la propia imagen y a la protección de la juventud y de la infancia».

68 Roig Torres, M., «Los delitos de racismo y discriminación (arts. 510, 510bis, 511y 512)», GonZÁLEz Cussac (Dir.), Comentarios a la reforma del Código Penal de 2015, Valencia, Tirant lo Blanch, 2015, p. 1210.

69 De nuevo recordemos la STC 214/1991, de 5 de diciembre.

70 STEDH de 15/03/2011, caso Otegui Mondragon c. España. Idem en la sentencia de 13/03/2018, en el caso Stern Taulats y Roura Capellera c. España. Aunque de nuevo el TEDH vuelve a entender que el Tribunal Constitucional español había interpretado demasiado extensivamente las excepciones a la libertad de expresión 
El delito de incitación al odio o de discurso del odio ${ }^{71}$, por el que se investigó el tuit de VOX, se enmarca dentro de los delitos contra la Constitución. Es un delito que se comete en el ejercicio de los derechos fundamentales, —en este caso de la libertad de expresión-, y castiga a quienes «públicamente fomenten, promuevan o inciten directa o indirectamente al odio, hostilidad, discriminación o violencia contra un grupo, una parte del mismo o contra una persona determinada por razón de su pertenencia a aquél, por motivos racistas, antisemitas u otros referentes a la ideología, religión o creencias, situación familiar, la pertenencia de sus miembros a una etnia, raza o nación, su origen nacional, su sexo, orientación o identidad sexual, por razones de género, enfermedad o discapacidad» (art. 510 CP.1.a $)^{72}$. Además, se prevé un tipo agravado para el supuesto de que los hechos se realicen a través de internet u otras redes sociales, de modo que se hiciera accesible a un elevado número de personas (art. 510.3 CP), por el incremento del riesgo para el bien jurídico que ello supone. Por otro lado, el apartado segundo del mismo artículo 510 castiga a «quienes lesionen la dignidad de las personas mediante acciones que entrañen humillación, menosprecio o descrédito de alguno de los grupos a que refiere el apartado anterior, o de una parte...» (delito de odio $)^{73}$. Con independencia de que, efectivamente, las manifestaciones puedan causar daño a la dignidad de un grupo, las afirmaciones de Vox en el tuit en el caso que nos ocupa encajan más en el primer apartado del 510, el de la incitación al odio, pues, poca duda cabe de que buscaban públicamente fomentar la hostilidad hacia un colectivo, en este caso los inmigrantes, como puede derivarse de la lectura completa del tuit: «Imprescindible puntualizar el origen extranjero de la mayoría de los violadores para que los españoles tomen conciencia del tipo de delincuentes a los que estáis abriendo las puertas y subsidiando con el dinero de todos». En el delito de discurso del odio no se pena porque ello se considere una ideología reprochable, sino porque expresiones como estas fomentan en terceros una situación de hostilidad, discriminación o violencia hacia determinados colectivos. Se prevé un castigo porque su mensaje puede dar lugar a la aparición en quienes lo reciben de unas ideas de rechazo, de hostilidad (las de odio), que se consideran tan peligrosas y se valoran tan negativamente que se trata de impedir

en el caso concreto, volvió a reconocer esa posibilidad de limitar la libertad de expresión en el debate político en supuesto de discurso de odio o de incitación a la violencia.

71 Cuerda Arnau, M. L., «La libertad de expresión y crítica política a la luz de la jurisprudencia del TEDH», Teoría y Derecho: Revista de Pensamiento Jurídico, n. ${ }^{\circ} 13,2013$, pp. 221 y ss.

72 Presupuesto esencial de la nueva regulación que se dio con la Reforma del Código Penal en 2015, fue la Decisión Marco 2008/913/JAI, del Consejo de 28/11/2008, relativa a la lucha contra determinadas formas y manifestaciones de racismo y xenofobia mediante el Derecho Penal. A esa corriente marcada por el Tribunal Europeo de conceder un amplio margen a la libertad de expresión se ha venido acogiendo más recientemente nuestro Tribunal Constitucional, aún refiriéndose más a ofensas a la Jefatura del Estado o una Institución que al discurso del odio hacia colectivos, que es de lo que se trata en el caso que venimos analizando del tuit de VOX. (Véase STC 111/2019, de 2 de octubre y STC 6/2020, de 27 de enero).

73 Se incluye una agravante «cuando de ese modo se promueva o favorezca un clima de violencia, hostilidad, odio o discriminación contra los mencionados grupos». 
que puedan propagarse ${ }^{74}$. Es cierto que las palabras expresadas por VOX no generan una situación de violencia, pero sí pueden producir entre la ciudadanía actitudes de discriminación u odio hacia ese colectivo, lo que puede poner en peligro la dignidad, libertad o seguridad del mismo. El TEDH ha reconocido como delito de odio o como delito de discurso del odio supuestos en los que no se producía una incitación a la violencia contra un grupo, pero sí un ataque general a un grupo étnico y, a su vez, a la tolerancia, la paz social y la no discriminación (Asunto Kübnen c. Alemania, de 12 de mayo de 1988; asunto Norwood c. Reino Unido, de 16 de noviembre de 2004; asunto Belkacem c. Bélgica, de 27 de junio de 2017; asunto Féret c. Bélgica, de 16 de julio de 2019) ${ }^{75}$

En segundo lugar, no puedo estar más en desacuerdo con la decisión judicial cuando argumenta que el daño se diluye por cuanto las acusaciones no iban dirigidas a personas concretas - identificadas o identificables - sino contra todo un grupo étnico. Una manifestación de esta naturaleza constituye una falsedad deliberada, con la que se quiere reforzar un programa ideológico, que resulta del todo ilegítima por atacar deliberadamente la dignidad y/o honor de un colectivo e intentar crear un sentimiento de rechazo hacia el mismo, no importa que no fuera dirigida a individuos concretos con nombre y apellidos; esto que digo encajaría perfectamente con la doctrina establecida por el Tribunal Constitucional en el asunto de Violeta Friedman (STC 214/1991, de 5 de diciembre ${ }^{76}$ y con el hecho de que, tratándose de un presunto delito de incitación al odio (art. $510 \mathrm{CP}$ ), el desvalor de la actuación es el mismo si los mensajes van dirigidos a un individuo, como si van contra un colectivo.

$\mathrm{Y}$, en tercer lugar, considero que la sentencia yerra al considerar que el ejercicio de la libertad de expresión/opinión no encuentra también un límite en la veracidad de la base factual sobre la que se asienta. En el asunto Jerusalén c. Austria, el TEDH recuerda que, incluso cuando una declaración constituya el ejercicio de la libertad de expresión, al estar emitiéndose un juicio de valor en un debate político, la proporcionalidad de una injerencia en otros derechos y, por lo tanto, su no amparo en tal libertad, puede depender de si existe una base fáctica suficiente para la declaración impugnada, ya que incluso un juicio de valor sin ninguna base fáctica que lo sustente puede ser excesivo ${ }^{77}$. El tuit de

74 Galán Muñoz, A., «Delitos de odio, discurso del odio y Derecho penal», op. cit., pp. 68 y 69.

75 Puede verse también el trabajo de Mendoza Calderón, S., «Discurso del odio e inmigración. La criminalización de la intolerancia en el Derecho penal español», GALÁn MUÑOz, A. y MENDOZA CALDERón, S., Globalización y lucha contra las nuevas formas de criminalidad transnacional, Valencia, Tirant lo Blanch, 2019, pp. 265-308.

76 El Tribunal Constitucional indicaba que «el odio y el desprecio a todo un pueblo o a una etnia son incompatibles con el respeto a la dignidad humana, que sólo se cumple si se atribuye por igual a todo hombre, a toda etnia, a todos los pueblos. Por lo mismo, el derecho al honor de los miembros de un pueblo, etnia, en cuanto protege y expresa el sentimiento de la propia dignidad, resulta, sin duda, lesionado cuando se ofende y desprecia genéricamente a todo un pueblo o raza, cualesquiera que sean» (STC 214/1991, de 17 de diciembre, F.J. 8).

77 STEDH de 27/02/2001, par. 53. Idem en De Haes and Gijsels c. Bélgica, 24/02/1997, par. 47, y Oberschlick. Austria (no. 2), de 1/07/1997, par. 33. 
VOX, que nos sirve de ejemplo para lo que pretendo defender, venía a completar una información que había sido publicada por un periódico en el que este informaba de la violación de una mujer por cinco individuos. Estaba aportando una información fáctica, aunque obviamente con una marcada carga ideológica e intencionalidad política, lo que, en aplicación de la regla de ponderación entre libertad de expresión y libertad informativa, hace situar la actuación en el marco de la libertad de expresión. Pero, ello no es óbice para que, respecto de la parte del mensaje donde se transmite un hecho (la nacionalidad de los autores del delito), no recaiga, aunque sea mínimamente, la exigencia de la debida diligencia, de un ápice de la veracidad a la que se ha hecho referencia más arriba en este trabajo; y en este caso, no es ya que se fuera poco diligente a la hora de transmitir los hechos, sino que el «error» en el dato derivó de la mala fe de su autor/es, hubo una intención de transmitir unos hechos que dañan a un colectivo, a sabiendas de que son falsos, lo cual guarda similitud con el límite que la libertad tiene en la prohibición de la calumnia, que prohíbe «la imputación de un hecho delictivo hecha con conocimiento de su falsedad o temerario desprecio por la verdad». De hecho, lo que se pretende con el delito de calumnia es proteger el honor o dignidad de la persona y pivota sobre la actitud que tiene el autor frente a la verdad. A esta cuestión de la intención de mentir quisiera referirme ahora con más detenimiento.

\section{DE LA IDEOLOGÍA PERSONAL A LA FALSEDAD DELIBERADA O LA INTENCIÓN DE MENTIR}

Decíamos que ninguna opinión es evidente por sí misma, pues en cuestiones de opinión ni hay verdades ni opera el límite de la veracidad, como sí sucede con el ejercicio de las libertades informativas y la transmisión de hechos. Desde el punto de vista de la libertad ideológica, sobre una cuestión pueden surgir todo tipo de puntos de vista antagónicos y los mensajes que contienen una opinión tienen un margen de actuación muy amplio.

Pero, ¿cualquier mensaje, expresado pretendidamente como opinión, es posible dentro del ejercicio de la libertad ideológica o la libertad de expresión? $¿ \mathrm{O}$, además de los límites que el ordenamiento les establece, a los que nos hemos referido, hay unas reglas del juego que hay que respetar? Esto es importante en el ámbito de la política donde la difusión de los programas de partido o de idearios puede buscar afianzarse públicamente mediante un pretendido ejercicio de la libertad ideológica, cuando en realidad no esconden más que afirmaciones falsas, o el uso de datos parcialmente ciertos, con la exclusiva intención de generar daño o rechazo hacia determinadas personas o colectivos o desacreditar a quien está en el poder, entre otros objetivos.

La cuestión es que a veces se ha utilizado la estrategia de anular ciertas verdades incómodas extendiendo opiniones que las contradicen, o la de trasmitir 
datos falsos, y se ha hecho convenciendo de que, en el plano de las ideas, las opiniones valen igual que las verdades ${ }^{78}$.

Esa intención de hacer valer una mentira o unos datos o hechos falsos como si de una nueva opinión se tratase ha sido usada no solo por gobiernos, sino también por poderes sociales o económicos, grupos de interés, o movimientos o partidos políticos que desean influir en la opinión pública. La diseminación permanente y reiterada en el tiempo de determinados mensajes, - medio ciertos, o incluso falsos-, puede llevarse a cabo vistiéndolos de un pretendido ejercicio de la libertad ideológica. El peligro es que, efectivamente, ello puede acabar convirtiendo dichos mensajes en una opinión más tan válida como otras; y convencer de que son amparables en un Estado ideológicamente plural mensajes que son radicalmente contrarios a las reglas más básicas de un Estado democrático, sus valores y derechos. Se ha perdido el decoro hasta tal punto que, como veíamos más arriba, algunos mensajes políticos acaban vistiendo de idea política u opinión alternativa lo que no son más que ataques a determinados colectivos como los inmigrantes o los pertenecientes a una determinada religión o los no heterosexuales, o los movimientos feministas, o se presentan como una opinión afirmaciones que seriamente pueden conducir a un elevado riesgo frente a enfermedades como la provocada por el Covid-19, por poner algunos ejemplos. Y lo peor es cuando ello se hace empleando hechos o datos que manifiestamente faltan a la verdad.

Hay personas que sustentando determinadas opiniones pueden desacreditar fácilmente a la verdad factual, convirtiendo la transmisión de un hecho falso en otra opinión más. Incluso la reiteración mayoritaria de determinadas opiniones puede convertir una realidad en una mentira o viceversa. La facultad de persuasión de determinados líderes puede auspiciar ciertas opiniones que acaban generando un relato público que se asume como verdad. Se produce así una mezcla entre opinión e información, entre las ideas y los hechos, entre la información factual y las intenciones, de innegable peligro.

En este punto sería interesante recalar en el Informe del Consejo de Europa sobre el desorden informativo de $2017^{79}$, donde, apoyándose en la intencionalidad, distinguía entre lo que es: (a) Desinformación (Dis-information), que englobaría todo ese conjunto de mentiras y falsedades intencionadas a las que nos hemos venido refiriendo y que son creadas deliberadamente para herir a una persona, a un grupo social, a un gobierno o a un país. (b) Información errónea (Mis-information), aquella información que, aún no siendo verdadera, no ha sido creada con la intención de causar daño. Y (c) la información nociva (Mal-information), información que puede ser cierta, pero que se ha utilizado intencionadamente para causar daño a una persona, grupo social, organización o país. No solo la información falsa, sino

78 Sahuí Maldonado, A., «Verdad y política ...», op. cit., p. 92.

79 Wardle, C. y Derakhshan, H., Council of Europe Report (DGI (2017)09) on Information disorder: Toward an interdisciplinary framework for research and policy making, Council of Europe publications, 2017. 
también la veraz puede ser usada con fines desinformativos y dañar derechos fundamentales. Así, son conocidos los casos en los que se ha recurrido al uso de una especie de juego de acoso público a una persona o partido mediante la publicación online de información personal en momentos clave, o de fotos íntimas u otros datos que puedan generar el descrédito público, dañando derechos de la personalidad ${ }^{80}$. Igualmente, en el ejercicio de la libertad informativa se han ofrecido en ocasiones datos parciales sobre extranjeros encarcelados en un país, o cifras engañosas sobre inmigrantes autores de violencia de género ${ }^{81}$, que, aún siendo relativamente ciertos, por estar sacados intencionadamente de contexto, ser parciales y usarse con un fin determinado (lo cual les resta esa inicial certeza), podríamos pensar que faltan a la veracidad, (1) por la inexactitud o incomplitud del relato fáctico, y (2) por la intencionalidad maliciosa de faltar a la verdad.

Decimos esto último porque, volviendo al caso Jerusalén c. Austria, hemos de volver a recordar que, incluso moviéndonos en el exclusivo ámbito de la libertad de opinión, el TEDH ha señalado que «a las opiniones ha de exigírseles que se realicen con criterio o, al menos con sinceridad. Asimismo, incluso cuando una declaración equivale a un juicio de valor (...) debe tener suficiente base factual — coincidencia con el referente externo- - sin lo cual sería excesiva» (STEDH de 27 de febrero de 2001, caso Jerusalén c. Austria, par. 43).

La conclusión es que, en el panorama de la desinformación, a veces, no solo cabe atender al contenido de los mensajes y al daño que puedan generar, sino también a las motivaciones de los actores que los crean y los distribuyen, a la intencionalidad. Aún así, reconozco que esto tiene al menos dos problemas: a) Las intenciones, como todo lo que se halla en el interior de los individuos o se pergeña en los despachos de un gobierno, de un partido político o de un movimiento ciudadano, son simples potencialidades. Ha de admitirse que es difícil demostrarlas. b) La intencionalidad (maliciosa) en la expresión de ciertos mensajes es algo que cabe entrar a controlar solo cuando estamos ante un mensaje que se basa en una mentira y daña ilegítimamente intereses de terceros o del Estado.

\section{CONTROLES EN LA RED DE LOS MENSAJES FALSOS}

Un instrumento fundamental para conformar la opinión pública y auspiciar cualquier tipo de sentimiento colectivo, sea de responsabilidad (generalmente auspiciada por los poderes públicos) o de miedo (por cualquier fuente), son los medios de comunicación y, más aún, las redes sociales. Como decíamos al comienzo de este trabajo, la era digital ha conseguido que cualquier tipo de idea o información tenga

80 Marwick, A. y Lewis, R., Media manipulation and disinformation online, Data \& Society, 2017, pp. 11-12.

81 Martín Plaza, A., «Los bulos y desinformaciones de Vox sobre la violencia machista y su mezcla con la violencia doméstica», RTVE Noticias, 9/01/2019. 
una capacidad de difusión como nunca hubiésemos imaginado. Y las redes son también el lugar donde las noticias falsas (al igual que los mensajes xenófobos o discriminadores) han encontrado un campo abonado para hacerlos crecer ${ }^{82}$.

Los Gobiernos de los Estados miembros e instituciones de la UE, lejos de buscar una posible responsabilidad de estos medios digitales por la circulación de contenidos ilegales y/o falsos en sus plataformas ${ }^{83}$, han lanzado una llamada de colaboración a los mismos, y especialmente a las grandes empresas tecnológicas, para frenar la propagación de informaciones fraudulentas que inundan la $\operatorname{Red}^{84}$, y se ha reclamado un compromiso común similar al seguido en la lucha contra la propagación de determinados mensajes como los xenófobos o los de contenido terrorista sobre la que se lleva más tiempo trabajando.

La desinformación y la radicalización de discursos que incitan al odio son dos fenómenos distintos que guardan similitud en cuanto al ámbito donde proliferan — la red-, y porque la misma desinformación — las falsedades o mentiraspuede propiciar discursos de odio o discriminación. Por ello, las soluciones que ya se han avanzado para la lucha contra esa radicalización de determinados discursos supremacistas, xenófobos o excluyentes, tal vez, podrían ser usadas para el control de las fakes en internet.

Ambos fenómenos vienen siendo considerados como una amenaza de magnitudes insospechadas desde hace ya unos años. De ahí que tanto Gobiernos como instituciones supranacionales (entre ellas la Unión Europea) estén en alerta y hayan adoptado medidas para luchar contra $u^{85} \mathrm{y}^{85}$ el otro ${ }^{86}$, o incluso contra

82 Pauner Chulvi relata cómo gran parte de las noticias falsas son creadas por spammers, como se viralizan a través de redes sociales como Facebook o Twitter, como se usan los conocidos como trolls y otros instrumentos de creación y difusión de bulos, Pauner Chulvi, C., «Noticias falsas y...», op. cit., pp. 301 y 302. Véase también el interesante trabajo: Ава CAтогra, A.: «Desórdenes informativos en un sistema de comunicación democrático», RDP, n. ${ }^{\circ} 109,2020$, pp. 119-151.

83 La lógica exclusión de responsabilidad de los prestadores de servicios o de la red social es la regla general asentada en nuestro ordenamiento y en la de nuestros países vecinos. Sobre ello véase: Boix PALOP, A., «La construcción de los límites a la libertad de expresión en las redes sociales», REP, n. ${ }^{\circ} 173$, pp. 55-112.

84 Teruel Lozano, G., «Libertad de expresión en Internet, control de contenidos de las páginas web y sus garantías constitucionales», Revista Aranzadi de Derecho y Nuevas Tecnologías, n. ${ }^{\circ}$ 25, 2011, pp. 81-103.

85 La ONU expresó en 2017 su preocupación por el tema en la Declaración conjunta sobre Libertad de Expresión y Noticias Falsas, Desinformación y Propaganda (3 de maro de 2017). La UE en 2018 aprobó un Plan de Acción contra la desinformación y recientemente la Comisión Europea, en la nueva Estrategia de Seguridad de la Unión para el periodo 2020-2025 (24 /06/2020) hacía hincapié en la lucha contra «las campañas de desinformación y la radicalización de la narrativa política». M. Arenas analiza también diversas medidas legislativas que los Estados han ido adoptando para proteger el debate político y la formación de la opinión pública frente a las campañas de desinformación en la red, especialmente durante las campañas electorales. Así, en noviembre de 2018, se aprobó en Francia una Ley para combatir la manipulación de la información durante los períodos electorales (Loi $n^{\circ}$ 2018-1202 relative à la lutte contre la manipulation de l'information). También en 2018, en junio, en el Reino Unido, la Comisión Electoral Británica pidió una mayor transparencia para los votantes con respecto a la práctica de las campañas electorales digitales, haciendo recomendaciones sobre la responsabilidad, el gasto y la trasparencia Digital campaigning. Increasing transparency for voters). Arenas Ramiro, M., «Partidos políticos, opiniones políticas e internet: la lesión del derecho a la protección de datos», TRC, n. ${ }^{\circ} 44,2019$, p. 344.

86 Entre las medidas adoptadas para luchas contra el discurso del odio en el ámbito de la UE, cabe aludir al Código de conducta contra el discurso ilegal del odio a través de Internet, aprobado en 2016, adoptado en el 
ambos conjuntamente ${ }^{87}$. Se trata de una batalla que ha de librarse no solo en cada Estado, sino también en la esfera supranacional, pues dichos fenómenos utilizan principalmente internet y las redes sociales como vía de difusión, y estas operan ajenas a las fronteras nacionales. De hecho, la UE se encuentra ahora en proceso de elaboración de un paquete legislativo, que se englobará en la Ley de Servicios Digitales que profundizará, entre otras cosas, en la cuestión de las responsabilidades de los servicios digitales y la protección de los derechos fundamentales de los usuarios en línea, entre otras cosas frente a contenidos o servicios ilegales. La normativa se encuentra en fase de consulta pública hasta finales de 2020 y podría constituir una oportunidad abierta para introducir algún tipo de garantías frente a la desinformación en red.

La primera pregunta es ¿cómo se pueden realizar controles frente a ese tipo de mensajes que circulan por la red?

Tal vez, en el caso de los mensajes de carácter xenófobo o discursos radicales, sea más fácil aplicar técnicas de cribado algorítmico que buscan palabras o perfiles determinados entre la infinidad de mensajes que pueden corren cada segundo en internet y, aún así, no es descartable que se produzcan errores; pero la detección de posibles bulos (por no hablar de las falsedades) es materialmente más dificultoso. Resulta infinitamente más arduo por la complejidad técnica de encontrar cómo realizar ese filtrado, que no puede ser tan automático como cuando se buscan términos xenófobos concretos, por poner un ejemplo. Los expertos se inclinan por defender que el juicio humano, y el establecimiento de paneles de expertos (fact-checkers) que realicen las comprobaciones pertinentes, es una herramienta mucho más fiable que el recurso a los algoritmos. Pero, en segundo lugar, lo más difícil es cómo hacerlo diferenciando lo que son solo medias verdades de las indiscutibles falsedades o mentiras. Es muy complicado realizarlo de una manera neutra y sin caer en el error de eliminar mensajes que son manifestación de la libertad ideológica o de la libertad informativa, que pueden estar erradas, pero no entrarían dentro del concepto de bulo. La verdad no siempre es fácil reconocerla y, a veces, hasta algunas barbaridades son aceptables en democracia. Como veíamos más arriba, se admiten posiciones negacionistas sobre la existencia del Holocausto cuando encontraríamos infinidad de pruebas acerca de su existencia.

La cuestión está en encontrar, entre los mensajes publicados en red, aquellos contenidos excesivos o ilegítimos que, faltando a la veracidad, ponen en riesgo el pluralismo informativo, el derecho a una información veraz y la sana competencia

marco de la Estrategia para el mercado único digital de la Comisión Europea; o la Recomendación (UE) 2018/334 de la Comisión Europea, de 1 de marzo, sobre medidas para combatir eficazmente los contenidos ilícitos en línea. En Francia, en mayo de 2020 se aprobaba la Loi visant à lutter contre les contenus haineux sur internet (Ley contra el discurso del odio en internet)

87 Alemania adoptó recientemente la Ley sobre la mejora de la aplicación de la ley en las redes sociales (Netzdurchsetzunggesetz, NetzDG), que contempla multas elevadísimas para las redes sociales si se oponen a borrar de sus plataformas mensajes fake o que inciten al odio. 
política por contravenir o dañar derechos, valores o principios esenciales en nuestra democracia. E, insistimos, eso técnicamente es complejo por las razones que se han esgrimido, siendo los paneles de expertos independientes la fórmula que más consenso suscita.

La segunda pregunta es quién debe realizar ese control. Los cuerpos de seguridad e inteligencia de la gran mayoría de los Estados, al considerar la desinformación como una amenaza para la seguridad nacional, llevan tiempo desarrollando programas de prevención, concienciación y control de este tipo de mensajes. En el caso de España, la Orden ministerial de octubre de 2020, que citaba más arriba, refiere a la realización de actuaciones de monitorización y vigilancia (detección, alerta temprana, notificación y análisis) con el objetivo de detectar campañas de desinformación y su análisis ante su posible impacto en la seguridad nacional, así como como para el apoyo en la gestión de situaciones de crisis (como el caso de la Covid-19) donde pudiera haber una afectación derivada de dichas campañas. Sin embargo, se trata de una orden meramente enunciativa, que hace un esbozo de la estructura orgánica de actuación frente a la desinformación, sin aludir a una regulación más precisa y sin hacer ninguna referencia a las garantías que, respecto de los derechos a la libertad de expresión, de información, de privacidad o de autodeterminación informativa, deberán adoptarse. No hace falta recordar que lo relativo a esa posible limitación de derechos fundamentales y las garantías que, en su caso, hayan de adoptarse deberá recogerse en una norma con rango de ley y de carácter orgánico y tendrá que atender a las previsiones constitucionales.

Pero, además de las fuerzas de seguridad del Estado o quien determine cada Estado, hemos de preguntarnos qué responsabilidad tienen los servidores de comunicaciones electrónicas en la lucha contra la difusión por las redes de ese tipo de mensajes falsos.

Obviamente, esa lucha contra la desinformación no puede llevarse a cabo sin la concurrencia de las empresas de distribución de contenidos y proveedoras de servicios de internet, porque es principalmente en esas plataformas donde se ubican muchos de los mensajes a los que hemos venido refiriéndonos en este trabajo. Se ha considerado que dichas empresas tienen responsabilidades a efectos de contribuir a la lucha contra los contenidos ilícitos o falsos difundidos a través del uso de sus servicios. Esto se incluye en lo que se denomina Corporate Social Responsability (CSR) o responsabilidad social corporativa de las empresas, un concepto que emergió en los años cincuenta. Se trata de una forma de dirigir las empresas basado en la gestión de los impactos que su actividad genera sobre sus clientes, empleados, accionistas, comunidades locales, medioambiente y sobre la sociedad en general.

Respecto de los contenidos ilícitos, muchas de estas grandes compañías inicialmente quisieron mantener una actitud neutral en lo que refiere al ejercicio de la libertad de expresión por los usuarios de sus plataformas. Su argumento era que la libertad de expresión es de crucial importancia en las sociedades democráticas y cualquier tipo de censura iría en contra de la libre circulación de información y 
opiniones. Además, arguyeron que no se les puede hacer responsables de controlar la ingente cantidad de información que circula por sus plataformas, ya que no disponen ni del personal ni de las herramientas necesarias para luchar contra las opiniones y para identificar los mensajes falsos.

Sin embargo, con el tiempo, las propias empresas, de forma voluntaria, han ido adoptando mecanismos para hacer un filtrado de noticias falsas a través de equipos de evaluadores of fact-checkers independientes ${ }^{88}$ y eliminar o establecer una etiqueta de «posible fake» para aquellos mensajes que manifiestamente falten a la verdad. Este nuevo camino se emprendió desde que, en 2018, Facebook, Google, Microsoft, Mozilla, Twitter y siete asociaciones comerciales europeas firmaran el Código de buenas prácticas contra la desinformación ${ }^{89}$. Igualmente, se han abierto sitios web que buscan detectar y hacer públicos bulos que circulan por las redes (Maldita.es, Newtral, EFE Verifica, \#StopBulos, Snopes, la Buloteca, Hoaxy, CazaHoax, FactCheck.org, ...)

Así, por poner algunos ejemplos de la nueva actitud de las plataformas que ofrecen servicios de datos y comunicaciones electrónicas, Twitter a finales de mayo de 2020 subrayó que un tweet de Donald Trump no era verdadero, aunque no lo eliminó, simplemente advertía de ello $^{90}$. Facebook retiraba también, un mes después, un anuncio de campaña de Trump por contener simbología nazi ${ }^{91}$ y Twitter cerraba su cuenta por incitación a la violencia en enero de 2021 tras el asalto al Capitolio. Igualmente, tanto Twitter como Facebook le advirtieron por dar «información engañosa»sobre el Covid ${ }^{92}$. La misma compañía Facebook a finales de enero de 2020 había bloqueado alguna de las funciones de la cuenta oficial de Vox por incitación al odio y el partido presentó una querella contra Twitter. A mediados de abril del mismo año, se abrió una nueva disputa con Vox como protagonista, esta vez contra Whatsapp por limitar los reenvíos de mensajes, acusándole de que la aplicación censuraba los mensajes críticos con el Gobierno, falsedad que el propio servicio de mensajería se vio obligado a desmentir. La plataforma aclaró que simplemente se trataba de una medida aplicada globalmente que limitaba los reenvíos en un intento de frenar la difusión de bulos (fundamentalmente sobre el Covid-19) a través de su canal. Igualmente, Facebook ha reaccionado contra el Presidente brasileño, Jair Bolsonaro, suspendiendo

88 Pauner Chulvi, C., «Noticias falsas y libertad de expresión...», op. cit., p. 305.

89 Auspiciado por la Comisión Europea, el Code of Practice on Disinformation, se puso en marcha en octubre de 2018 dentro del Plan de acción contra la desinformación de la UE.

90 También Trump afirmaba en un tweet a raíz de los altercados y protestas en Minneapolis, a finales/05/2020, como consecuencia de la terrible muerte de un detenido negro por un policía blanco, que «Cuando empiezan los saqueos, empiezan los disparos. ¡Gracias!». Este mensaje fue calificado por Twitter de incitador a la violencia, no borrándolo, pero sí advirtiendo de ello antes de poder entrar a su lectura. Sin duda, afirmaciones de este tipo son peligrosísimas, además de deplorables, por lo que pueden incitar a aquellos que son sus seguidores ciegos.

91 Prieto, M., «Facebook retira anuncios de la campaña de Donald Trump, Expansión, 20/06/2020.

92 LABorde, A., «Trump equipara la covid con la gripe y Twitter y Facebook le advierten por dar información engañosa», El País, 6/10/2020. 
dos cuentas de su entorno que se usaban para difundir mensajes políticos de desinformación ${ }^{93}$.

Además de esa colaboración voluntaria, la normativa ya lleva unos años estableciendo la obligación de borrado en las plataformas de contenidos que resulten ilegales a petición de la autoridad correspondiente, generalmente un juez o cuando reciban una denuncia de cualquier persona al respecto ${ }^{94}$, aunque tales previsiones están pensadas para cuando los contenidos constituyen discurso del odio o la discriminación, cuando pueden violentar algún derecho fundamental de los ciudadanos o cuando atenta a los derechos de autor o de propiedad intelectual, y menos para la eliminación de noticias falsas, salvo que estas incurran en alguna de estas actuaciones.

Lo que genera más dudas es si se podría obligar (forzar) a las grandes empresas suministradoras de información telemática a llevar a cabo una labor prospectiva, a tener que realizar un barrido de lo que se publica para que detecten posibles bulos, como se ha hecho respecto de otro tipo de mensajes como los xenófobos o terroristas. De hecho, como acabo de indicar, en cierta medida, parece que ya lo están haciendo de una forma voluntaria.

Desde mi punto de vista, las medidas que las empresas proveedoras de servicios de red están implementando en su lucha contra las fakes en las redes o aquellas que pudiesen derivarse de normas que impongan el deber de hacerlo, si van exentas de la participación de un juez o de una comisión independiente de control, me parecen muy peligrosas. Por mucho que queramos luchar contra los mensajes falsos vulneradores de derechos o que emponzoñan el libre debate político, el cribado del que hablamos constituye una tarea compleja que puede conducir a limitaciones erróneas (o buscadas) del ejercicio de las libertades ideológicas e informativas. Por eso se hace muy necesario el establecimiento de protocolos y sistemas de control que se rijan por la transparencia y la independencia. Soy consciente de que esta cuestión requeriría de un estudio más detenido, entre otras cosas, sobre la prohibición de la censura previa (art. 20.2 CE) y las medidas de autorregulación interna, y que ahora, por limitaciones de espacio, no es posible abordar ${ }^{95}$. Requeriría también reflexionar, como se ha hecho en la jurisprudencia norteamericana ${ }^{96}$, sobre la consideración de dichas plataformas como foros públicos, foros privados o con una naturaleza intermedia y las consecuencias que ello puede conllevar para las limitaciones a los contenidos en ellas recogidos.

93 VeGA, G., «Facebook suspende dos cuentas de noticias falsas asociadas a Jair Bolsonaro», El País, $9 / 07 / 2020$.

94 Véase, por ejemplo, las previsiones de la Directiva 2000/31/CE de comercio electrónico, o la Recomendación (UE) 2018/334 de la Comisión Europea, de 1 de marzo, sobre medidas para combatir eficazmente los contenidos ilícitos en línea.

95 Véase: Teruel Lozano, G., «Libertad de expresión y censura en internet», Estudios de Deusto, Vol. 62/2, 2014, pp. 41-72.

96 Un estudio a este respecto puede verse en VÁzquez Alonso, V. J., «Twitter no es un foro público per el perfil de Trump sí lo es. Sobre la censura privada de y en las plataformas digitales en los EE UU», Estudios Deusto, vol. 68/1, 2020, pp. 475-508. 


\section{A MODO DE CONCLUSIÓN: «FIAT VERITAS NE PEREAT $M U N D U S »$}

En el ámbito de la discusión pública y el intercambio de información, la verdad absoluta no existe. En democracia todo puede ser puesto en entredicho o puede ser criticado hasta tal extremo que haga dudar sobre la certeza de casi cualquier cuestión que inicialmente se asumía como verdadera. Caben pocas verdades absolutas.

Pero, el que no exista la verdad absoluta no significa que podamos vivir en la incertidumbre constante sobre todo aquello que nos rodea o sobre lo que se nos informa. El desorden informativo no beneficia ni a los derechos fundamentales ni a la propia democracia, más bien al contrario, erosiona sus cimientos. Vivir inmersos en un marco informativo infinito en el que los hechos noticiables veraces conviven en paridad con medias verdades, falsedades o fakes genera en los ciudadanos inseguridad en el mejor de los casos, —en el supuesto de aquellos que aún se interrogan sobre la certeza de lo que leen o escuchan-, y, en el peor de los casos, esclavitud ideológica o intelectual, —cuando de una forma acrítica los ciudadanos acaban arrastrados (manipulados) por el mensaje que más se repite-.

La Constitución reconoce el derecho a recibir información veraz ${ }^{97}$, que constituye uno de los principales fundamentos de la realidad democrática, supone la condición sine qua non para consolidar una opinión pública plural y libremente formada ${ }^{98}$, pero no podemos hablar del derecho fundamental a recibir información verdadera ni el derecho fundamental a no recibir información falsa. No existe la libertad negativa a no recibir información manipulada o tendenciosa, a no ser víctima de la desinformación. Lo que se trata es de garantizar la libertad en el proceso comunicativo, de tal forma que se pueda recibir todo tipo de mensaje y quede en manos del receptor la libertad de elegir la información o las opiniones que decida leer o escuchar, sean estas provenientes de fuentes sólidas o lo sean de fuentes o informaciones que vulgarmente calificamos como «basura» ${ }^{99}$. Lógicamente, ello

97 Ausín DíEz, T., «Contar y no mentir: sobre el derecho positivo a recibir información veraz», PEÑA, L. y Ausín DíEz, T., Los derechos positivos: las demandas justas de acciones y prestaciones, Plaza y Valdés-CSIC, 2006.

98 Así, «el art. 20 de la Norma fundamental, además de consagrar el derecho a la libertad de expresión y a comunicar o recibir libremente información veraz, garantiza un interés constitucional: la formación y existencia de una opinión pública libre, garantía que reviste una especial trascendencia ya que, al ser una condición previa y necesaria para el ejercicio de otros derechos inherentes al funcionamiento de un sistema democrático, se convierte, a su vez, en uno de los pilares de una sociedad libre y democrática. Para que el ciudadano pueda formar libremente sus opiniones y participar de modo responsable en los asuntos públicos, ha de ser también informado ampliamente de modo que pueda ponderar opiniones diversas e incluso contrapuestas» (STC 159/1986, de 16 de diciembre, FJ 6). Sobre la dimensión institucional de los derechos de expresión y de comunicación puede verse también el trabajo: SolOzABAL ECHAVARria, J. J., «Aspectos constitucionales de la libertad de expresión y el derecho a la información», REDC, n. ${ }^{\circ} 23,1988$, p. 142.

99 Villaverde Menéndez, I., «Los derechos del público...», op. cit., p. 131. De una forma más extensa puede consultarse la monografía del mismo autor: Los derechos del público: el derecho a recibir información del artículo 20.1.d) de la Constitución española de 1978, Madrid, Tecnos, 1995. 
tiene muchos peligros: nos encontramos con la dificultad del ciudadano medio de ser capaz no solo de recibir y procesar la avalancha de información que recibe, más aún en la era digital, sino también la de poder discernir cuál tiene visos de veracidad de la que simplemente constituye un bulo.

Estamos saturados de información y, entre toda esa información, unos mensajes acaban calando más que otros. Conforme a ellos actuamos, formamos nuestros juicios, establecemos creencias, nos manifestamos, escribimos opiniones y votamos para elegir a nuestros representantes. Por lo tanto, la desinformación puede hacer que acabemos ejerciendo nuestras opciones sobre hechos o realidades que no son ciertos y/o influidos por la reiteración de eslóganes falsos que discriminan o generan odio sobre determinados colectivos o pueden poner en riesgo valores y derechos de la ciudadanía, como la salud o la seguridad.

Hemos visto múltiples ejemplos del uso de técnicas persuasivas frente a la opinión pública, como las medio verdades o falsedades y las mentiras. También hemos comprobado como no es un comportamiento exclusivo de partidos supremacistas, populistas o de extrema derecha o izquierda, sino que, como han defendido diversos pensadores, parece que el campo de la política se encuentra más en relación y más cerca de servirse de la mentira que de cultivar la verdad o de alentarla.

En internet se ha observado una tendencia al alza en el uso de las técnicas de la mentira o la ficción por determinados líderes, partidos o movimientos políticos que libran una batalla por controlar la percepción de la opinión pública sobre el poder, los hechos o las necesidades del pueblo; buscan adueñarse del relato público: hoy puede ser el relato sobre el origen o la gestión de la pandemia ${ }^{100}$ como en el pasado lo ha sido sobre otras cuestiones. Para conseguir ese seguidismo acrítico de las masas que ellos persiguen, las redes sociales constituyen una plataforma de difusión sin precedentes, pues la reiteración a gran escala de determinados hechos falsos puede acabar convirtiendo una mentira en una opinión más. Y lo peor es cuando ese mensaje que trata de imponerse a la opinión pública, haciendo uso de las técnicas de la desinformación, es el del odio, de la discriminación o trata de minar la legitimidad de las instituciones democráticas.

Desde luego, ha de reconocerse la dificultad de la verificación de la ilegalidad o falsedad de ciertos mensajes sin quebrantar el sacrosanto principio del pluralismo ideológico y el derecho a las libertades de pensamiento e informativas. De hecho, señalaba Urías Martínez que la lucha contra las noticias inventadas puede hacer más daño a la democracia que su propia difusión, pues genera un riesgo elevado de que las medidas legislativas contra las noticias falsas se usen para silenciar los discursos disidentes con el poder ${ }^{101}$. Ello nos plantea tres cuestiones.

100 Аваd Soto, J., «La guerra de percepción en la crisis de la COVID-19», Documento de Opinión IEEE $n .^{\circ} 66,21 / 05 / 2020$.

101 URías Martínez, J., «La verdad os hará libres (si es obligatoria)», Contexto y Acción, 13/05/2020. 
La primera de las mismas consiste en determinar qué mensajes que faltan a la verdad son amparables en un Estado democrático de derecho y cuáles no son admisibles y, por lo tanto, son susceptibles de generar una responsabilidad civil o penal o de cualquier otro tipo en sus autores. ¿Podemos permanecer impertérritos ante discursos y mensajes falsos que emponzoñan el discurso público y ante partidos o movimientos que, para convencer a ese público y alcanzar el poder, usan de las artimañas de la mentira? ¿Acaso cabe permitir la libre expresión de ideas cuando estas se sustentan sobre mentiras y persiguen atentar contra principios o valores de nuestra Constitución como el pluralismo o la igualdad, por mucho que digamos que en democracia el pluralismo ideológico es su máxima y todo es opinable? Pues, ya se ha visto arriba que no siempre. Como hemos defendido, la veracidad de los elementos fácticos sobre los que se apoya una opinión cobra relevancia en muchas ocasiones, al igual que la intencionalidad (la mala fe o la voluntad de mentir) en la transmisión de hechos o de ideas sustentadas en hechos falsos.

En segundo lugar, y puesto que estos mensajes se difunden masivamente en las redes, tal vez, tengamos que plantearnos si hay que asumir que la revolución digital trae consigo también una suerte de disrupción jurídica en el sistema de la libertad de expresión y de información, debiéndose, por lo tanto, repensar los presupuestos desde los cuáles hemos venido juzgando los límites al ejercicio de estos derechos. Y todo ello teniendo en cuenta que esas posibles limitaciones pueden traer como consecuencia: (a) simplemente la cesión del ejercicio de las libertades de expresión y las informativas en favor del ejercicio de derechos de otros o la protección de bienes constitucionalmente protegidos (la seguridad nacional, la seguridad pública, la salud, la no discriminación...), pudiendo ser bloqueado su acceso o eliminados determinados contenidos; recordemos que los mensajes no veraces no disfrutan de la tutela constitucional del art. 20; (b) o pueden conllevar la exigencia de responsabilidad civil por mensajes falsos que puedan dañar derechos de la personalidad; o (c) incluso pueden suponer el que los mensajes falsos acaben sometidos a control y persecución, con la posibilidad adicional de exigir responsabilidades administrativas o penales a sus autores en ciertos supuestos.

Y la tercera cuestión es quién puede luchar contra ello, esto es, contra el fenómeno de la desinformación en sus diferentes manifestaciones, pero especialmente cuando hablamos de bulos. Si es el gobierno, se corre el riesgo de dejar en sus manos la determinación de cuál es la verdad oficial y qué se consideran mentiras. Si son las empresas que ofrecen servicios de datos e internet, también detrás de ellas existen intereses políticos y económicos que podrían hacer un uso interesado de ese control de los mensajes que se publican en sus plataformas. Esta es una cuestión aún abierta que requiere del establecimiento de mecanismos que, en todo caso, han de regirse por las reglas de la transparencia y de la independencia.

Como advertíamos en este trabajo, en demasiadas ocasiones algunos discursos políticos se vuelven homogéneos y emocionales, y pueden incluso apoyarse en mentiras, lo que acaba mermando la libertad individual de opinar, de criticar, de expresar las propias ideas, invisibiliza las voces disidentes y adormece la capacidad 
de reacción. Y, como decía Ferrajoli, «una democracia puede quebrar, aún sin golpes de estado en sentido propio, si sus principios son de hecho violados o contestados sin que sus violaciones susciten rebelión o, al menos, disenso ${ }^{102}$. Se hace pues necesario desenmascarar las mentiras para asegurar un debate público debidamente informado y no envenenado por las falsedades. Porque solo en ese caso será libre, o al menos más libre. Emulando el adagio latino «fiat iustitia et pereat mundus», cabría pensar en un «fiat veritas et pereat mundus» (Que se haga la verdad, aunque perezca el mundo), que vendría a entenderse como que la verdad ha de buscarse siempre sin reparar en el precio que puede costar o las consecuencias que puede acarrear. Si nos acogemos a esta interpretación deberíamos entrar en el difícil tema de si siempre es legítimo decir la verdad, cuestión que no podemos abordar ahora en un trabajo que tiene un objeto mucho más modesto. Pero, cabe optar por una segunda interpretación que se acerca al uso que Hegel dio al adagio latino: «Fiat iustitia ne pereat mundus» (que se haga la justicia para que no perezca el mundo), que trasladándolo a nuestro ámbito sería, «Fiat veritas ne pereat mundus», y significaría que la verdad ha de buscarse siempre, si no se quiere que el mundo se hunda en el caos. Ciertamente, la recurrente falta a la verdad en los últimos tiempos está conduciendo a un desorden informativo que puede arrastrarnos al caos; y han saltado las alarmas.

Siempre con el máximo respeto a las libertades de expresión y de información, procede pues tratar de desterrar la mentira, restablecer el orden propio de la opinión libre e informada y recuperar ese escenario donde intercambiar ideas sin juegos sucios. Solo en ese escenario de transparencia y de honestidad democrática es donde se puede contrargumentar y disentir en condiciones de los discursos que tratan de socavar los fundamentos y principios básicos de nuestro Estado.

$$
* * *
$$

TITLE: Falsehoods, fakes and other techniques disregarding truth in order to influence public opinion

ABSTRACT: In the world of superinformation featuring the Internet times, certain messages take root in the public opinion before other ones. This happens by hazard or, most often, intentionally. Falsehoods or fakes find a fertile ground to create opinions with proven potential to destabilize governments, influence elections or jeopardize important State values such as equality, dignity, pluralism, health, etc. Notwithstanding the lack of absolute truth in democracy, this article analyzes those statements issued by government, private citizens, associations or political parties, that, because of their absolute disregard for rigorous information or because of clear intention to deceive, cannot be admissible. This is so even if they are expressed in a political debate context as a result of free expression enjoyment. Democracy requires freedom of information, and demands participation, debate and opinion. In that interaction, nonetheless, minimum rules of the game —limits - must be respected so as to secure a basic democratic safeguard.

RESUMEN: En el mundo de la superinformación propio de la era de internet es donde determinados mensajes pueden acabar calando en la opinión pública frente a otros, cosa que puede suceder de manera fortuita o,

102 Ferrajoli, L. Poderes salvajes. La crisis de la democracia constitucional, Barcelona, Paidós, 2011, p. 22. 
en la mayor parte de las ocasiones, de una forma pretendida. Es abi donde las falsedades o las mentiras (fakes) pueden encontrar un terreno abonado para crear opiniones que tienen un demostrado potencial para desestabilizar gobiernos, influir en unas elecciones o poner en riesgo valores importantes del Estado (la igualdad, la dignidad, el pluralismo, la salud...). Aunque no existe una verdad absoluta en democracia y todo es opinable, en este artículo se analiza si hay afirmaciones, - bien provenientes del gobierno o de ciudadanos o de asociaciones o partidos politicos, no importa-, que, por su absoluto desprecio al rigor informativo o por su manifiesta intención de engañar, no son admisibles, incluso aunque se realicen en el marco del debate político $y$, por lo tanto, en el ejercicio de la libertad de expresión. Se defiende que la democracia exige libertad informativa, y exige participación, debate y opinión, pero en esa interacción hay unas minimas reglas de juego —unos límites — que deben respetarse si se quiere hablar de una garantía democrática básica.

KEY WORDs: truth, hoaxes, fakes, public opinion, lies, falsehoods, freedom of expression, freedom of information, truthful information.

Palabras Clave: verdad, bulos, fakes, opinión pública, mentiras, falsedades, libertad de expresión, libertad de información, información veraz.

FECHA DE RECEPCIÓN: 02.08.2020

FECHA DE ACEPTACIÓN: 26.01.2021 
